\title{
New heterodontosaurid remains from the Cañadón Asfalto Formation: cursoriality and the functional importance of the pes in small heterodontosaurids
}

\author{
Marcos G. Becerra, ${ }^{1}$ Diego Pol, ${ }^{1}$ Oliver W.M. Rauhut, ${ }^{2}$ and Ignacio A. Cerda ${ }^{3}$ \\ ${ }^{1}$ CONICET- Museo Palaeontológico Egidio Feruglio, Fontana 140, Trelew, Chubut 9100, Argentina 〈mbecerra@mef.org.ar〉; 〈dpol@mef.org.ar〉 \\ ${ }^{2}$ SNSB, Bayerische Staatssammlung für Paläontologie und Geologie and Department of Earth and Environmental Sciences, LMU München, \\ Richard-Wagner-Str. 10, Munich 80333, Germany〈o.rauhut@lrz.uni-muenchen.de〉 \\ ${ }^{3}$ CONICET- Instituto de Investigación en Paleobiología y Geología, Universidad Nacional de Río Negro, Museo Carlos Ameghino, Belgrano \\ 1700, Paraje Pichi Ruca (predio Marabunta), Cipolletti, Río Negro, Argentina〈nachocerda6@yahoo.com.ar〉
}

\begin{abstract}
New ornithischian remains reported here (MPEF-PV 3826) include two complete metatarsi with associated phalanges and caudal vertebrae, from the late Toarcian levels of the Cañadón Asfalto Formation. We conclude that these fossil remains represent a bipedal heterodontosaurid but lack diagnostic characters to identify them at the species level, although they probably represent remains of Manidens condorensis, known from the same locality. Histological features suggest a subadult ontogenetic stage for the individual. A cluster analysis based on pedal measurements identifies similarities of this specimen with heterodontosaurid taxa and the inclusion of the new material in a phylogenetic analysis with expanded character sampling on pedal remains confirms the described specimen as a heterodontosaurid. Finally, uncommon features of the digits (length proportions among nonungual phalanges of digit III, and claw features) are also quantitatively compared to several ornithischians, theropods, and birds, suggesting that this may represent a bipedal cursorial heterodontosaurid with gracile and grasping feet and long digits. In particular, the elongated non-terminal pedal phalanges and morphology of digit III resemble features present in arboreal birds, a unique condition found so far among ornithischians.
\end{abstract}

\section{Introduction}

Ornithischian dinosaurs were one of the most important herbivorous components of terrestrial vertebrate faunas along the second half of the Mesozoic, but many aspects of their early evolution and diversification patterns are currently unknown, given their poor representation in fossil assemblages from the Late Triassic to the Middle Jurassic (Sereno, 1997; Irmis et al., 2007). This has been a persistent problem in achieving a detailed understanding of the early differentiation of the major clades of ornithischians before the Late Jurassic-Early Cretaceous, and understanding the importance of small omnivoral-herbivoral niches occupied by these groups, which is important for assessing how ornithischians occupied the niches of large herbivores during the second half of their evolutionary history.

The Cañadón Asfalto Formation has yielded the richest and best studied microvertebrate faunal assemblages for the latest Early or early Middle Jurassic of South America (Rougier et al., 2007b; Escapa et al., 2008), including the recently described small-bodied heterodontosaurid Manidens condorensis Pol, Rauhut and Becerra, 2011 (the dentition of which was recently described by Becerra et al., 2014). Although Manidens Pol, Rauhut, and Becerra, 2011 is the most complete heterodontosaurid known from South America, it currently is represented by craniomandibular remains, the axial skeleton, a fragmentary pectoral girdle and a complete pelvis, and lacks fore and hind limbs.

In this communication, we describe a new ornithischian specimen from the Cañadón Asfalto Formation (MPEF-PV 3826), also found in the same locality and horizon as Manidens condorensis. MPEF-PV 3826 includes both metatarsi associated with several disarticulated pedal phalanges and caudal vertebrae with chevrons. This small-bodied specimen shows a combination of plesiomorphic features among ornithischians with heterodontosaurid apomorphies, some of which have been noted by Santa Luca (1980) for Heterodontosaurus tucki Crompton and Charig, 1962, and others are new characters identified in this study. The comparison of MPEF-PV 3826 with other ornithischian material is focusing mostly on small sized and closely related ornithischians. We also describe the histology of metatarsal IV and compare the overall similarity of the metatarsus with other ornithischians through a cluster analysis. Also, we add new information to a previous phylogenetic analysis (re-scoring of some heterodontosaurid taxa and adding 18 characters identified by Sereno [2012], and 11 new characters), including the addition of Pegomastax africanus Sereno, 2012 and MPEF-PV 3826 to test the affinities of the latter specimen. To infer possible aspects of mode of life of this 
specimen we also use the length proportion of pedal phalanges of digit III to perform a ternary diagram and a principal component analysis, and a comparison of the inner and outer curvature in pedal ungual phalanges with other dinosaurs and recent birds.

\section{Materials and methods}

The performed statistical analyses were used to provide complementary comparisons to those of the morphological description. The length of the metatarsals in MPEF-PV 3826 were measured using a digital caliper (accuracy $0.01 \mathrm{~mm}$, all measurements presented at Table 1 in Supplemental Data 1), while all measurements on comparative material where taken from photographs or the literature. The cluster analysis and claw curvature/behavior box plots were realized using the Infostat free version software (Di Rienzo et al., 2011). Ternary diagram and principal component analysis on length proportions of phalanges of digit III, and the claw-curvature/relative-thickness diagrams were performed using the software PAST, version 2.10 (PAlaeontological STastics, Hammer et al., 2001), with data presented by Hopson (2001) and Birn-Jeffery et al. (2012) and adding some ornithischian taxa. Although the database of Hopson (2001) was used without changes, several species sampled in the Birn-Jeffery et al. (2012) database were excluded because they lack the relevant information for the diagrams. With these data, box plots include 742 specimens for the inner curvature, 763 for the outer curvature, 742 specimens for the inner-curvature/relative-thickness graph, and 649 for the outercurvature/relative-thickness graph. Of these, 22 specimens correspond to Mesozoic theropods, eight to ornithischians, including MPEF-PV 3826, and the remaining specimens represent several families of recent birds and lizards (Birn-Jeffery et al., 2012).

To test the taxonomic affinities of this new specimen a cladistic analysis was performed, using the data matrix originally compiled by Butler et al. (2008), and including the changes in characters proposed by Pol et al. (2011) and others (see below). The data matrix includes 53 taxa and 259 characters and was analysed using equally weighted parsimony in TNT, version 1.1 (Goloboff et al., 2008a, 2008b).

To determine the growth pattern and the ontogenetic stage of the MPEF-PV 3826, a middiaphyseal cross section of metatarsal IV was taken. The cross-section was prepared using standard paleohistological techniques (Chinsamy and Raath, 1992) and studied under transmitted light, both normal and polarized. The terminology used follows the general terminology of bone histology described in Francillon-Vieillot et al. (1990) and Chinsamy-Turan (2005).

Abbreviations.-BP, Evolutionary Studies Institute, University of the Witwatersrand, Johannesburg, South Africa; IVPP, Institute of Vertebrate Paleontology and Paleoanthropology, Beijing, People's Republic of China; MB Museum für Naturkunde, Berlin, Germany; MCF-PVPH, Museo Carmen Funes, Paleontología de Vertebrados, Plaza Huincul, Neuquén, Argentina; MPEF, Museo Paleontológico Egidio Feruglio, Trelew, Chubut, Argentina; MUCPv, Museo de la Universidad Nacional del Comahue, Neuquen Province, Paleovertebrates;
NHMUK, Natural History Museum, London, United Kingdom; PVL, Instituto Miguel Lillo, Tucumán, Argentina; SAM, Iziko South African Museum, Cape Town, South Africa; STMN, Shandong Tianyu Museum of Nature, Pingyi, Shandong Province, People's Republic of China; YMP, Peabody Museum of Natural History, Yale University, New Haven.

\section{Systematic paleontology}

\section{Dinosauria Owen, 1842 \\ Ornithischia Seeley, 1887}

Heterodontosauridae Kuhn, 1966

Genus and Species Indeterminate

Figures 1-6, 9

Specimen.-MPEF-PV 3826, right and left medial distal tarsals, almost complete left and right metatarsus, associated with many scattered phalanges and caudal vertebrae with chevrons. This material has features unknown in other ornithischians (e.g., proportional length of pedal phalanges) but we refrain from erecting a new species, given that this specimen cannot be compared with the holotype of Manidens condorensis (found at the same locality and horizon) because of the lack of diagnostic overlapping material, and might even represent the same specimen as the holotype of the latter (see below).

Occurrence.-MPEF-PV 3826 was collected at the Queso Rayado Locality $\left(43^{\circ} 24^{\prime} 33,55^{\prime \prime} \mathrm{S} ; 69^{\circ} 13^{\prime} 50,1^{\prime \prime} \mathrm{W}\right)$, from outcrops that belong to the Cañadón Asfalto Formation, located at $5.5 \mathrm{~km}$ northwest of the village of the Cerro Condor, in Chubut province, Argentina. The vertebrate-bearing lithology at this microvertebrate locality was characterized as a silicified

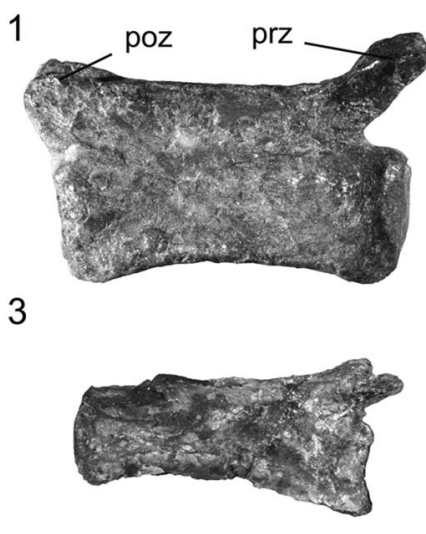

5

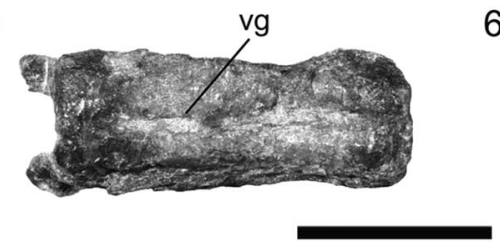

2

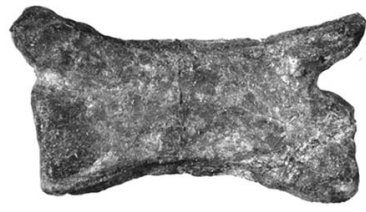

4

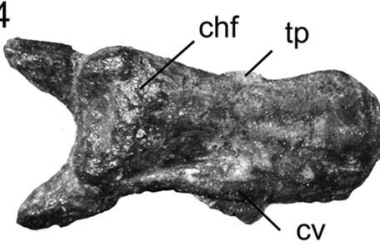

6

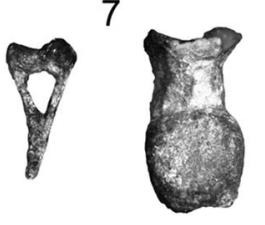

Figure 1. Indeterminate Heterodontosauridae MPEF-PV 3826, isolated caudal vertebrae and chevron: (1-3) caudal vertebrae in lateral view, positioned from proximal to distal elements; $(\mathbf{4}, \mathbf{5})$ caudal vertebrae in ventral view; (6) isolated hemal arch or chevron; (7) anterior view of isolated vertebra. chf, chevron facet; cv, chevron; poz, postzygapophysis; prz, prezygapophysis; tp, transversal process vg, ventral longitudinal groove. Scale bar equals $5 \mathrm{~mm}$. 

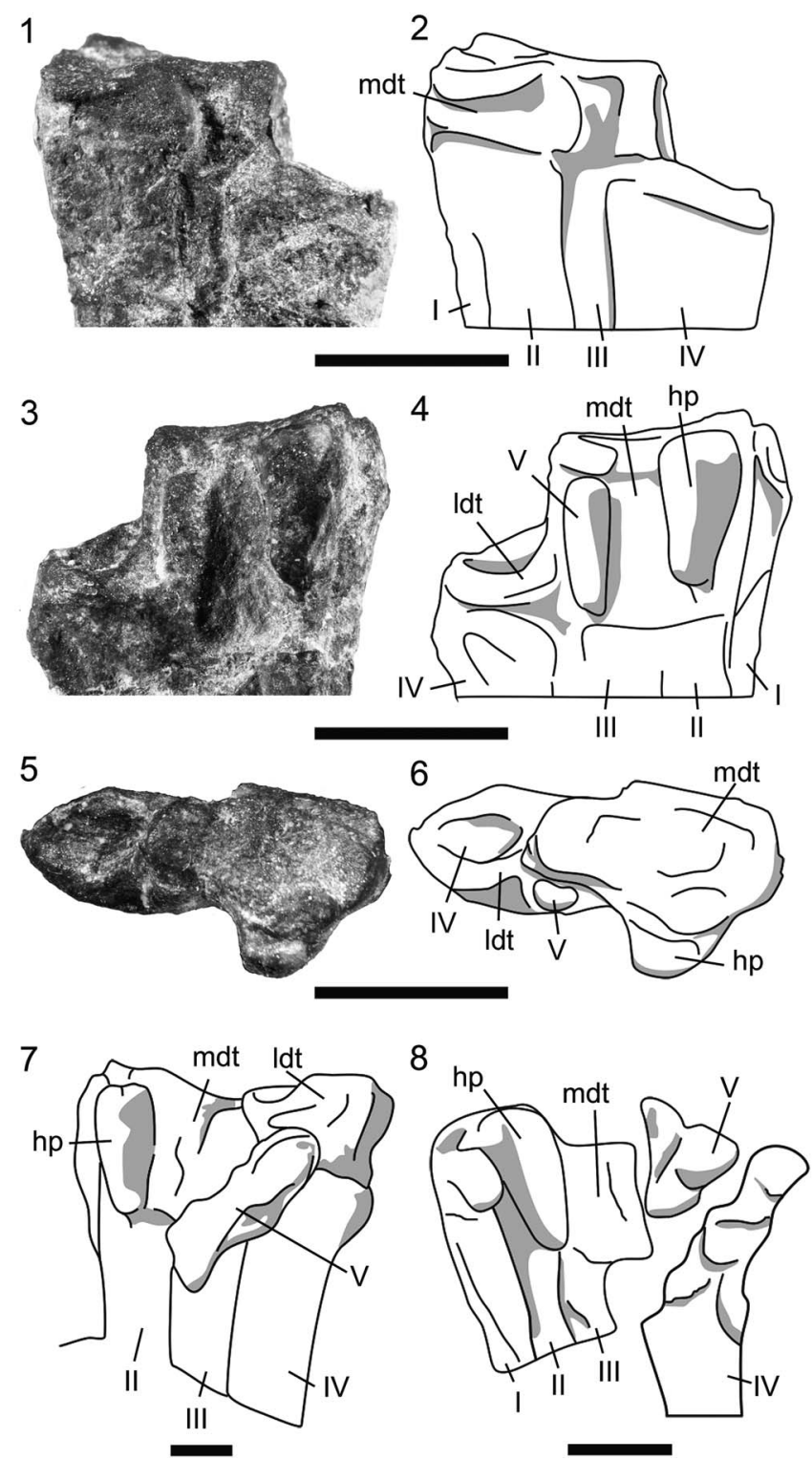

Figure 2. Indeterminate Heterodontosauridae MPEF-PV 3826, preserved tarsals and comparisons. $(\mathbf{1}, \mathbf{3}, \mathbf{5})$ Photographs; $(\mathbf{2}, \mathbf{4}, \mathbf{6}, \mathbf{7}, \mathbf{8})$ schematic line drawings. (1, 2) Anterior; $(\mathbf{3}, \mathbf{4})$ plantar; $(\mathbf{5}, \mathbf{6})$ proximal view of the preserved medial distal tarsal and the fragmented lateral tarsal of the left pes; (7) Heteterodontosaurus tucki, schematic line drawing of plantar view of tarsals and proximal metatarsals (modified from Santa Luca, 1980); (8) Tianyulong confuciusi, schematic line drawing of plantar view of tarsals and proximal metatarsals (modified from Zheng et al., 2009, supplementary material) I, metatarsal I; II, metatarsal II; III, metatarsal III; IV, metatarsal IV; $\mathrm{V}$, metatarsal V, represented as a reduced bone; hp, "hypotarsal-like" process, resembling the feature mentioned by Santa Luca (1980) for Heterodontosaurus; ldt, lateral distal tarsal; mdt, medial distal tarsal. Scale bars equal $5 \mathrm{~mm}$.

mudstone deposited in a shallow lacustrine environment with volcanic influences (Rougier et al., 2007a). This locality has been interpreted as belonging to the lowermost section of the Cañadón Asfalto Formation (Rougier et al., 2007a; Cuneo et al., 2013). The base of this unit has been recently dated as latest Early Jurassic (late Toarcian; Cuneo et al., 2013). The deposition of the Cañadon Asfalto Formation extended into the early Middle Jurassic, as indicated by other radiometric dates (Salani, 2007; Cabaleri et al., 2010) and recent palynological studies (Volkheimer et al., 2009; Zavattieri et al., 2010).

\section{Description}

Vertebral column.-Seventeen scattered caudal vertebrae are preserved in MPEF-PV 3826 and are closely associated with the metatarsals and phalanges, two of them being found partially articulated underneath the metatarsi (Fig. 1, see also Supplemental Data 2 and Supplemental Data 3). Some of the vertebrae are slightly crushed or distorted. All centra are spoolshaped, long and low, and vary more in their dorsoventral height than their length (Fig. 1.1-1.3). The width of the articular surface ranges between $28.6 \%$ and $36.6 \%$ of the length of each centrum (Fig. 1.7). The anterior articular surface is flat and the posterior articular surface is slightly concave, as in Fruitadens haagarorum Butler, Galton, Porro, Chiappe, Henderson, and Erickson, 2010 (Butler et al., 2012, fig. 11H-11I). The size and orientation of the pre- and postzygapophyses are similar in lateral view in all preserved vertebrae, but the prezygapophyses are more steeply dorsally inclined than the postzygapophyses (e.g., Fig. 1.1). In anterior and posterior view, the articular surfaces of the prezygapophyses are obliquely oriented (at $45^{\circ}$ with respect to the horizontal axis), whereas the postzygapophyseal surfaces stand almost vertically. The vertebral centra have a conspicuous longitudinal ventral groove (Fig. 1.4-1.5), which is poorly developed or absent in smaller and more distal vertebrae. The lateral surface of the centrum is slightly concave in transverse section. Only the largest vertebra has a smooth ventral chevron facet on the proximal end (Fig. 1.4). There are only two vertebrae that have a small transverse process (Fig. 1.4) preserved on the left side. The small size of the transverse processes resembles the transverse processes of the middleposterior caudal vertebrae of Heterodontosaurus Crompton and Charig, 1962. The neural spine is only a slightly developed longitudinal ridge in the larger, more proximal vertebrae, and is completely absent in the smaller (more distal) elements. There is no evidence of ossified tendons in the caudal vertebrae, as in Heterodontosaurus, but differing from the situation in Tianyulong confuciusi Zheng, You, Xu and Dong, 2009. In all preserved vertebrae, the sutures between the neural arches and centra are completely closed, a condition that might be related to an advanced ontogenetic stage (Brochu, 1996; Irmis, 2007).

In comparison with Heterodontosaurus (Santa Luca, 1980), the reduction of the neural spine and transverse processes described above indicates that these elements belong to the medial-distal portion of the tail, resembling the condition in Friutadens Butler, Galton, Porro, Chiappe, Henderson, and Erickson, 2010 (Butler et al., 2012). The more distal vertebrae are not only less robust and dorsoventrally lower, but their centra also become rod-shaped (rather than spool-shaped). There is only small variation in centrum length between the preserved vertebrae in MPEF-PV 3826 and the size of pre- and postzygapophyses, regardless of their position in the tail (in contrast to the development of the transverse processess and neural spines), as commonly seen in medial-distal caudal vertebrae within Dinosauria (i.e., Weishampel et al., 2004). The holotype (MPEF-PV 3211) of the heterodontosaurid Manidens includes one described proximal caudal, the length of which is equal to the length of the anterior-most preserved vertebrae of MPEF-PV 3826 (Pol et al., 2011; personal observation). 
1

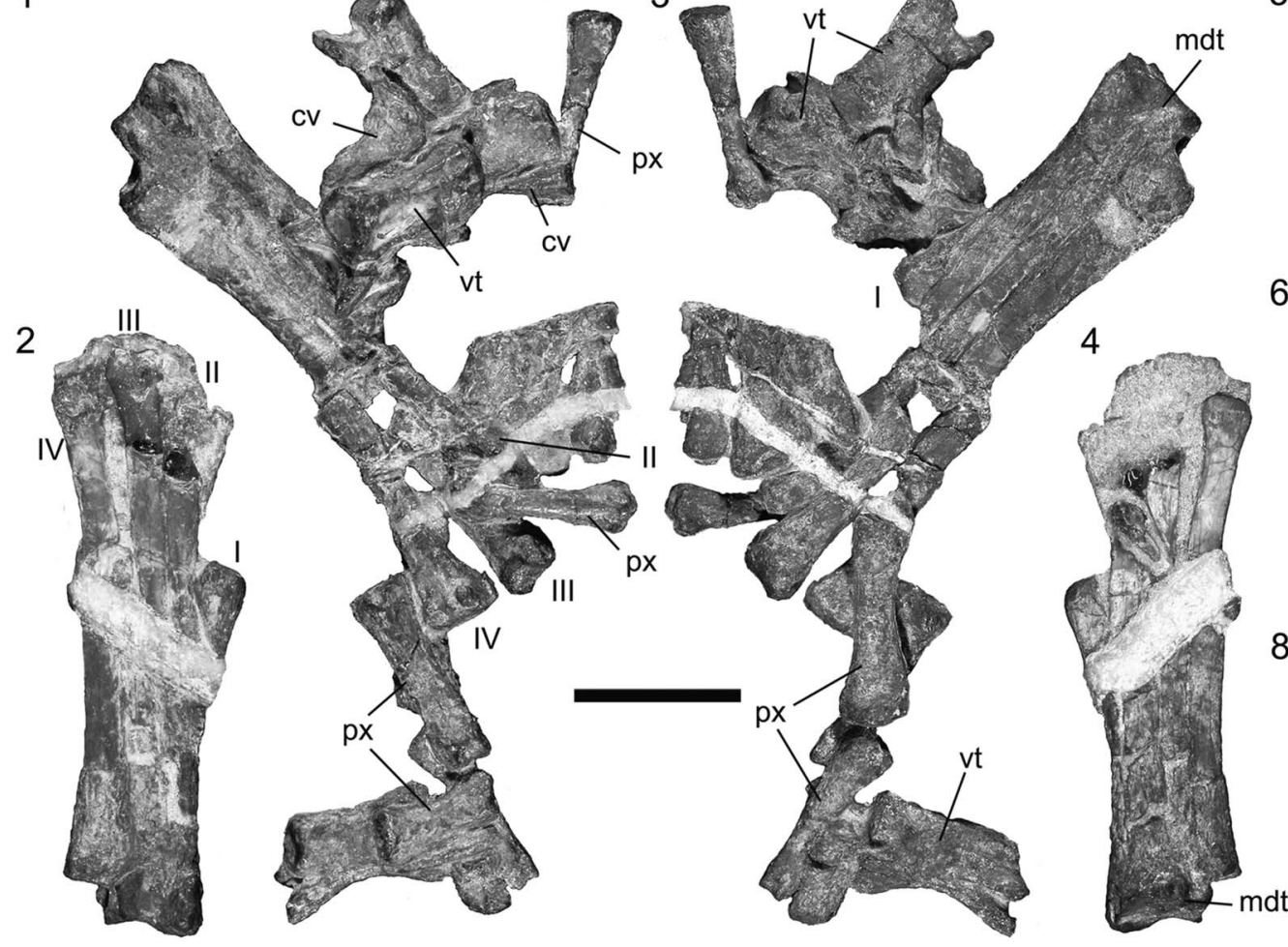

5
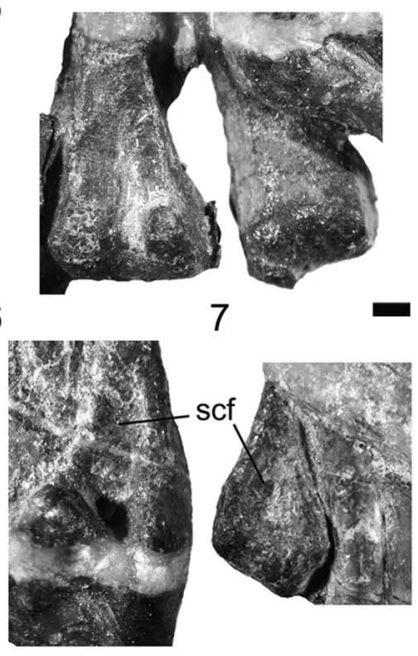

8

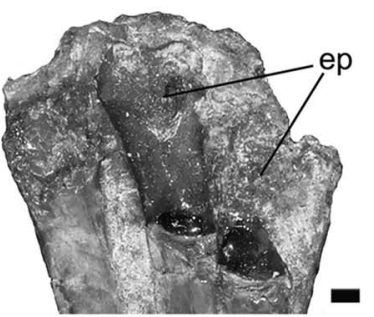

Figure 3. Indeterminate Heterodontosauridae MPEF-PV 3826. Metatarsals and scattered phalanges and caudal vertebrae: (1, 3) left and (2, 4) right metatarsals and fused tarsals in plantar $(\mathbf{1}, \mathbf{2})$ and anterior $(\mathbf{3}, \mathbf{4})$ view; $(\mathbf{5 - 7})$ distal condyles in plantar view of metatarsal IV (5, left); metatarsal III (5, right); metatarsal II (6); and metatarsal I (7); (8) cast on rock representing the distal condyles of metatarsals II (right) to IV (left) in anterior view. I, metatarsal I; II, metatarsal II; III, metatarsal III; IV, metatarsal IV; cv, chevron; ep, extensor pit; mdt, medial distal tarsal; px, phalanx; scf, supracondylar fossa; vt, cervical vertebrate. Scale bars equal $1 \mathrm{~cm}$ for (1-4) and $1 \mathrm{~mm}$ for $(\mathbf{5}-\mathbf{8})$.

Chevrons.-There seem to be only seven preserved chevrons, which are partially covered and scattered among the elements of MPEF-PV 3826 (Fig. 1.4, 1.6; see also Supplementary Data 2 and Supplementary Data 3). The rod-like shaft of the chevrons is laterally compressed, but the proximal expansion is weak, as in Heterodontosaurus posterior to the sixth chevron (Santa Luca, 1980). This condition is also commonly found in basal ornithopods (i.e., Hypsilophodon foxii Huxley, 1869 and Thescelosaurus neglectus Gilmore, 1913 in the middle caudal region, proximal chevrons in Gasparinisaura cincosaltensis Coria and Salgado, 1996). The widest portion of the chevron corresponds is the proximal articular surface in both lateral and posterior views. Although the distal portion of the largest chevron is slightly expanded anteroposteriorly, there is no evidence of distal widening of the chevrons in MPEF-PV 3826. The comparison with Heterodontosaurus suggests that the preserved chevrons belong to the caudalmost vertebrae that have chevrons, which are usually placed at the middle portion of the caudal series. This is consistent with the inferred position of the preserved caudal vertebrae mentioned above. The chevrons of MPEF-PV 3826 are dorsoventrally higher than the neural spine of the preserved vertebrae, as in the middle section of the caudal series of Heterodontosaurus, Gasparinisaura Coria and Salgado, 1996, and basal ornithischians. Other taxa, such as Dryosaurus altus (Marsh, 1878); Thescelosaurus Gilmore, 1913; Hypsilophodon Huxley, 1869 and more derived ornithopods, have chevrons at the middle section of the caudal series that are equal or shorter than the neural spine.
Autopodium.-The autopodium is represented by complete right and left metatarsi, in both cases including the medial distal tarsals and associated phalanges. The metatarsus is composed of five metatarsals, which are proximally fused, as in the cursorial heterodontosaurids Heterodontosaurus and Tianyulong Zheng, You, Xu, and Dong, 2009 (Fig. 2.7-2.8).

Tarsus.- The distal tarsus consists of two elements, the common condition in ornithischian dinosaurs (Norman et al., 2004), including Heterodontosaurus (Sereno, 2012). The medial distal tarsal is complete (Fig. 2.1-2.6) and the lateral distal tarsal is represented by a small bone fragment (Fig. 2.3-2.6). An unusual characteristic among ornithischians is that the preserved tarsals are strongly coossified to each other and to the metatarsus (Fig. 2.1-2.4). This is a widespread feature in theropods (i.e., Olmólska, 1981), especially birds, but has only been reported in Heterodontosaurus (Santa Luca, 1980) and Tianyulong (at least in the medial distal tarsal [Sereno, 2012]) among ornithischians. Even though the distal tarsals and the metapodium are not preserved in Fruitadens Butler, Galton, Porro, Chiappe, Henderson, and Erickson, 2010, it is worth noting that there is coossification of the distal tibia, fibula, and proximal tarsals in this taxon, as in the other heterodontosaurids Heterodontosaurus and Tianyulong (Santa Luca, 1980; Butler et al., 2012; Sereno, 2012). This feature might be functionally related to the fusion of the tarsomentatarsi here reported for MPEF-PV 3826, but it might be worth noting that it is absent in Abrictosaurus and seems to be variable in Heterodontosaurus 


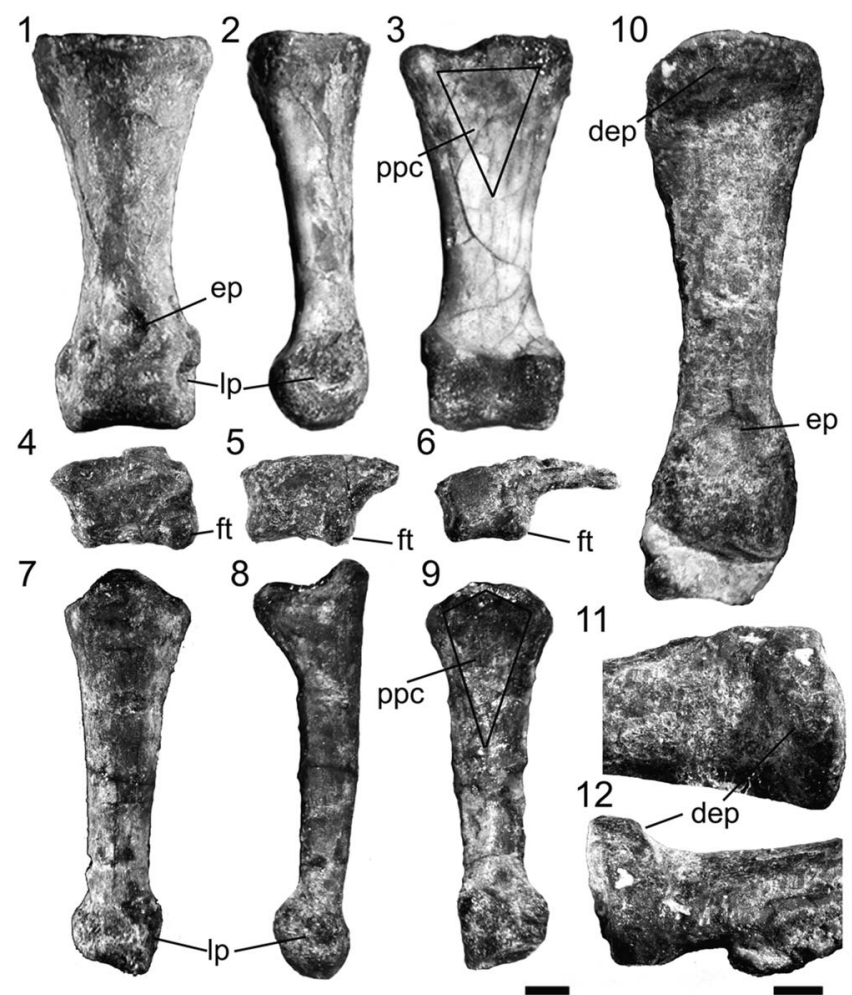

Figure 4. Indeterminate Heterodontosauridae MPEF-PV 3826, phalanges of the pes; $(\mathbf{1 - 3}, \mathbf{1 0 - 1 2})$ examples of robust phalanx in dorsal (1), lateral (2) and plantar view (3); (4-6) three of four isolated ungual phalanges in lateral view; (7-9) example of slender phalanx in dorsal (7), lateral (8), and plantar view (9); (10) first phalanx of digit III; $(\mathbf{1 1}, \mathbf{1 2})$ detail of dorsal extensor process on first phalanx of digit III (character 259:1) in dorsal (11) and lateral (12) views. dep, dorsal extensor process; ep, extensor pit; ft, flexor tubercle; lp, lateral pits; ppc, proximoplantar concavity, for interphalangeal pulley joint muscles. Scale bars equal $1 \mathrm{~mm}$

(Sereno, 2012). The medial distal tarsal is the largest element of the distal tarsus and is coossified with metatarsals I, II, III, and V (the latter being represented by a strongly reduced splint of bone positioned on the plantar side of the metatarsus, Fig. 2.3-2.6), with an obliterated sutural line. The medial distal tarsal has a squared proximal articular surface that is lateromedially concave and anteroplantarly convex (Fig. 2.5-2.6). The plantar surface of this tarsal bears a proximodistally elongated process overhanging metatarsal II (Fig. 2.3-2.4), as it is also present in Heterdontosaurus (Santa Luca, 1980; Norman et al., 2004; Fig. 2.7) and Tianyulong (STMN 26-3; see Zheng et al., 2009, supplementary material; Fig. 2.8). This was interpreted as a functional equivalent of the hypotarsal ridge (Baumel and Witmer, 1993) of extant birds (Santa Luca, 1980), related to the attachment of the flexor tendons of the digits. In proximal view, this process forms a plantar protuberance of the medial distal tarsal. A similar morphology was described for Orodromeus makelai Horner and Weishampel, 1988 and Jeholosaurus Xu, Wang, and You, 2000a (Han et al., 2012), but the development of this process is notably reduced in comparison with the condition seen in heterodontosaurids (see below: Phylogenetic Analysis).

The lateral distal tarsal is located over the proximal portion of metatarsal IV, and it is represented only by a small bone fragment (Fig. 2.3-2.6). This bone fragment is located on the plantar side of the proximal articular facet of the metatarsal IV

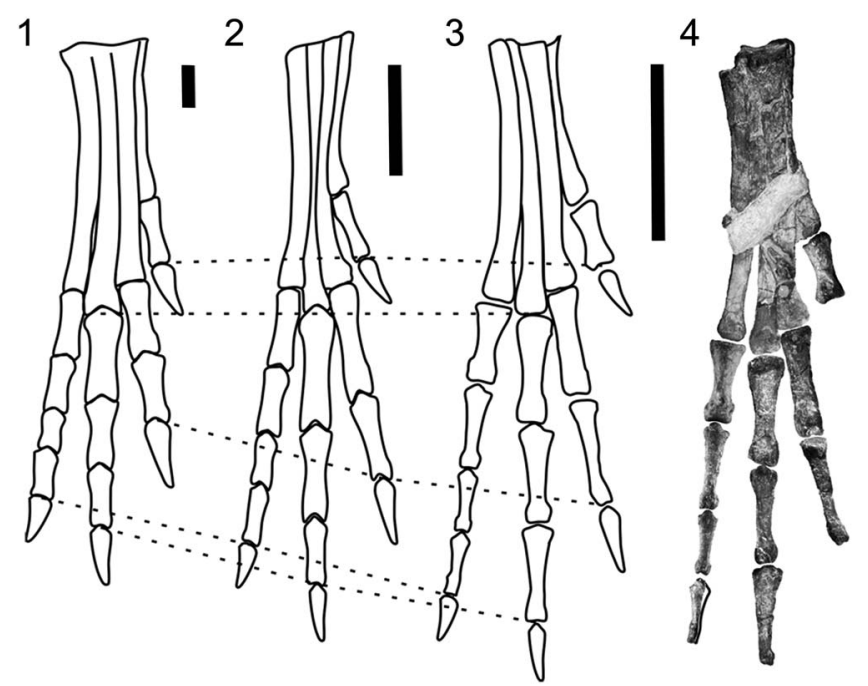

Figure 5. Indeterminate Heterodontosauridae MPEF-PV 3826, reconstruction of the pes and comparison with other heterodontosaurid taxa; metatarsals drawn to subequal size and aligned to compare the digit length among heterodontosaurids with the size of the pes: (1) Heterodontosaurus tucki, simplified schematic drawing modified from Sereno (2012); (2) Tianyulong confuciousi, schematic drawing that combines the shape of the metatarsaus of specimen STMN 26-3 (Zheng et al., 2009) with the phalangeal measurements of the more complete specimen IVPP V17090 from Sereno (2012), with metatarsal proportions re-scaled to aproximate the phalangeal measurements; (3) MPEF-PV 3826, schematic line drawing of right foot in anterior (dorsal) view; (4) reconstruction of the pes of MPEF-PV 3826, with distal portions represented by the cast preserved on rock. Phalanges I-1 and IV-1 were specularly rotated to aval orientation. For comparisons, dashed lines mark the distalmost point of metatarsal 3 and the end of each digit (without counting the ungual phalanx). Scale bars equal $2 \mathrm{~cm}$.

and is likely to be fused, while the rest of the articular surface of metatarsal IV remains exposed. The lateral distal tarsal fits into the deeply concave proximal surface of metatarsal IV (Fig. 2.3-2.6). This feature (in contrast to the presence of a flat proximal articular surface of metatarsal IV), suggests that the lateral tarsal was tightly integrated in the tarsometatarsus and probably fused to the metatarsus, resembling Heterodontosaurus (Santa Luca, 1980; Sereno, 2012), rather than the condition described for Tianyulong (Sereno, 2012).

Metatarsus.-The left metatarsus is complete but fractured, with slightly displaced fragments of the shafts (Fig. 3.1, 3.3), and the right metatarsus is distally incomplete (Fig. 3.2, 3.4), preserving only the cast of the distal ends of the metatarsals II, III, and IV in the matrix (Fig. 3.8). The metatarsals were found in natural articulation and are proximally coossified to each other, though with recognizable suture lines between them (Fig. 2.1-2.4). Similar to the condition in other ornithischian dinosaurs, the weight bearing elements were metatarsals II, III, and IV. Metatarsal I is considerably shorter than metatarsals II-IV, and metatarsal V is represented only by a small splint of bone, which is located proximo-plantarly on the metatarsus and fused to the plantar surface of metatarsal III and the medial distal tarsal. The reduction of metatarsals I and V is a plesiomorphic feature for Ornithischia (Weishampel et al., 2004), and is present in numerous representatives of this clade, including Heterodontosaurus tucki (Santa Luca, 1980), Othnielosaurus consors Galton, 2006 (=Laosaurus consors Marsh, 1894), Thescelosaurus neglectus (Gilmore, 1915), Agilisaurus 

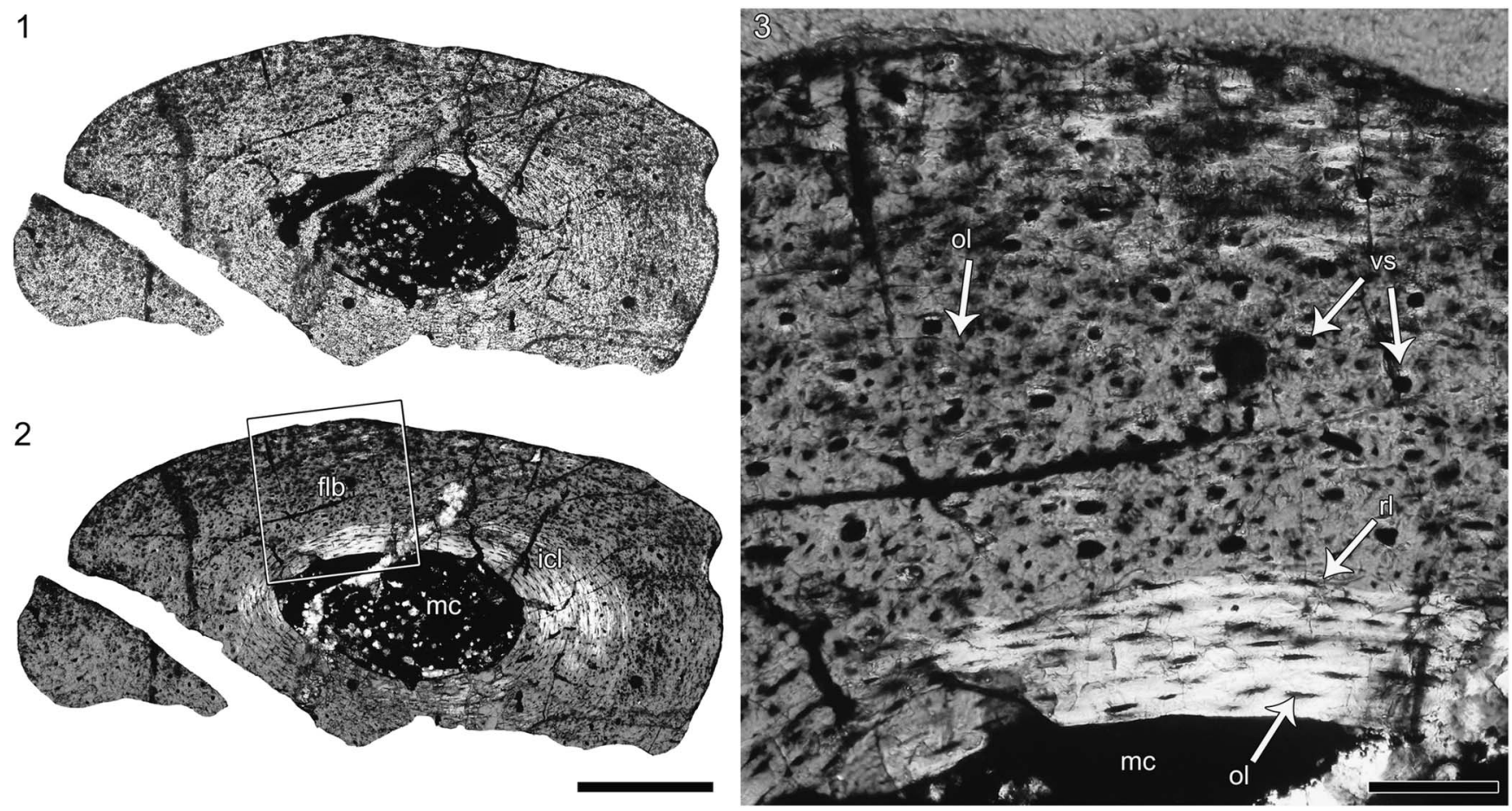

Figure 6. Indeterminate Heterodontosauridae MPEF-PV 3826: histological photographs of the middle shaft of left metatarsal 4. (1, 2) General view in normal (1) and polarized light with lambda compensator (2). (3) Detail of the cortical tissue in viewed under polarized light with lambda compensator (box inset in 2). Note the slight change in the intrinsic fiber arrangement at the outer cortex. flb, fibrolamellar bone; icl, inner circumferential layer; mc, medullary cavity; ol, osteocyte lacunae; lm, lamellar bone; rl, resorption line; vs, vascular spaces. Scale bar equals $0.5 \mathrm{~mm}$ in $(\mathbf{1}, \mathbf{2})$ and $0.1 \mathrm{~mm}$ in $(\mathbf{3})$.

louderbacki Peng, 1990 (Peng, 1992), and Gongbusaurus wucaiwanensis Dong, 1989. In anterior view, metatarsal III is proximally pinched between metatarsals II and IV, similar to the condition described in Gasparinisaura (Coria and Salgado, 1996), but not to the degree seen in arctometatarsalian theropods (Holtz, 1994). Metatarsals II-IV remain closely appressed to each other down to the midshaft, whereas metatarsal IV deflects slightly laterally.

Metatarsal I is a slender bone that is closely appressed to metatarsal II down to the proximodistal midpoint of the latter, but its distal condyle is deflected medially (Fig. 3.2, 3.4). The distal condyle is robust and twisted along its length (approximately $80^{\circ}$ ), so that the medial surface of this bone faces anteromedially at the distal end. The proximal region of metatarsal I, which reaches the tarsus, is slender, being almost $31 \%$ of the mediolateral width and $68 \%$ of the anteroplantal depth of metatarsal II. A proximally slender metatarsal I is a widespread feature among basal ornithischians. The contact of metatarsal I with the tarsus was considered to be an autapomorphic feature of Archaeoceratops oshimai Dong and Azuma, 1997, by You and Dodson (2004), but this condition is commonly found in ornithischians that have an elongated metatarsal I. For instance, a proximal contact between the medial distal tarsal and metatarsal I, as it is present in MPEF-PV 3826 , is also found in other heterodontosaurids (Tianyulong and Heterodontosaurus), Anabisetia Coria and Calvo, 2002, and Lesothosaurus Galton, 1978 (Sereno, 1991). Metatarsal I reaches the proximal-most portion of the metatarsus and probably contacted a cartilaginous continuation of the tarsals in Othnielosaurus Galton, 2006, Tenontosaurus Ostrom, 1970 and Thescelosaurus, as noted for Hypsilophodon (Galton, 1974b). Furthermore, a contact between these two bones is a widespread condition among basal dinosaurs (basal Saurischia [Langer, 2004]; some basal sauropodomorphs, such as Anchisaurus Marsh, 1885 [Galton and Upchurch, 2004a] and Efraasia minor Huene, 1908 [SMNS 17928, following Yates, 2003]). The rudimentary metatarsal I does not contact the tarsals in Camptosaurus dispar (Marsh, 1879) (Gilmore, 1909), Dryosaurus altus, Dysalotosaurus lettowvorbecki Virchow, 1919, and Iguanodon Mantell, 1825, and this element is completely lost in hadrosaurs (Gilmore, 1909; Norman, 1980; Galton, 1981). The common presence of this feature among basal species of Ornithischa and other basal dinosaurs suggests that the proximal contact of the medial distal tarsal and metatarsal I is a plesiomorphic condition of Dinosauria, and its presence in Archaeoceratops oshimai should be interpreted as retention of the plesiomorphic condition rather than an autapomorphic feature, being the most parsimonious assumption.

In MPEF-PV 3826, metatarsal I is proximally fused with metatarsal II (e.g., Figs. 2.1-2.4, 3.2), as in Tianyulong and Heterodontosaurus (Sereno, 2012; Fig. 2.7-2.8) and the medial distal tarsal (Fig. 2.3-2.4), as in Heterodontosaurus (Santa Luca, 1980; Fig. 2.7). Distally, the trochlear portion is similar in its mediolateral width to that of all other metatarsals, but is medially deflected (approximately $15^{\circ}$ in respect to the shaft of metatarsal II, Fig. 3.7). In distal view, the articular surface for phalanx I.1 is anteroplantarly wide, with the anteriormost portion of the trochlea exceeding the shaft in height, forming an anteroplantarly projecting articular trochlea in anterior view. 
This feature widens the arc of flexion of the first phalanx of digit I, a feature not mentioned previously for any heterodontosaurid. In plantar view, the intercondylar groove of the distal trochlea is less deep and the condyles are less bulbous than in other metatarsals. However, there is a deep supracondylar fossa in plantar view that is absent in all other metatarsals (Fig. 3.7). A similar fossa is present but shallower in Tianyulong (STMN 26-3). This deep fossa likely served for the attachment of flexor ligaments of digit I. In medial view, the collateral ligament groove of the distal metatarsal I for ligament attachment is replaced by a tubercle, a condition not observed in other heterodontosaurids. A similar tubercle is also present on the lateral side of distal metatarsal I, as can be observed in plantar view; both structures are here related to ligament attachment. Based on the identification of phalanx I.1 (see below) and the average length of all preserved ungual phalanges, digit I most probably exceeded the length of metatarsal II. This represents the plesiomorphic condition within Ornithischia, which is present in heterodontosaurids (e.g., Heterodontosaurus, Santa Luca, 1980; Tianyulong, Zheng et al., 2009) and other basal taxa (Othnielosaurus [Galton and Jensen, 1973]; Psittacosaurus Osborn 1923 [Osborn, 1924]; Archaeoceratops Dong and Azuma, 1997 [You and Dodson, 2003]).

Metatarsal II is of constant width throughout its length and slightly shorter than metatarsal IV, being approximately $86 \%$ the length of metatarsal III. The element is straight along its proximal half and has a slight medial deflection toward the distal condyle, a feature most noticeable in plantar view (Fig. 3.1, 3.3). The plantar surface, which contacts the proximal half of the metatarsal I, is anteroplantarly enlarged by a thin lamina that projects plantarly, but the anteroplantar width of metatarsal II in this region does not exceed that of metatarsals III and IV, contrasting with the well-developed plantar lamina of basal ornithopods, such as Anabisetia (MGB, personal observation), Othnielosaurus (Galton and Jensen, 1973), and Dryosaurus (Galton, 1981, fig. 15E, 15F). A deep extensor pit is present anteriorly above the distal condyle (Fig. 3.8), in contrast to the condition in Abrictosaurus Hopson, 1975, and Heterodontosaurus, which only have extensor pits in metatarsal III and metatarsal III and IV, respectively (Sereno, 2012). The lateromedial width of the distal condyle is larger than its anteroplantar depth. A supracondylar fossa is present on the plantar surface, but it is shallower than that of metatarsal I.

Metatarsal III is the longest element of the pes. It is straight but has a slightly laterally oriented distal condyle, resembling the condition in Abrictosaurus, but differing from Heterodontosaurus (Sereno, 2012). The distal end of metatarsal III has a well-developed extensor pit, as in Abrictosaurus, Tianyulong (specimen IVPP V17090; Sereno, 2012, fig. 28) and Heterodontosaurus (Santa Luca, 1980). In contrast to the widespread condition in ornithischians, the mediolateral width at the midshaft of metatarsal III is narrower than that of metatarsals II and IV in both anterior and plantar views, being 50\% narrower than metatarsal II and $17 \%$ narrower than metatarsal IV (Fig. 3.1-3.4). Moreover, metatarsal III is also narrower than metatarsal II and IV at the proximal end, and only along its distal third it becomes broader. A similar condition is present, but less developed in Heterodontosaurus and Abrictosaurus (SAM-PKK1332, MGB personal observation; NHMUK RU B54, Sereno,
2012, fig. 37), and it may also be present in Tianyulong but cannot be determined with confidence based on the published material (STMN 26-3, IVPP V17090). Although this feature is more conspicuous in MPEF-PV 3826 than in other heterodontosaurids, it does not reach the arctometatarsalian condition of certain theropod clades (Holtz, 1994). The appressed configuration of the metatarsals seems to represent a mechanical response to cursorial bipedality (Holtz, 1995).

Finally, metatarsal IV is the second longest bone in the metapodium (approximately $96 \%$ the length of metatarsal III), as in other heterodontosaurids, but also resembling the condition of many other bipedal ornithischians (Stormbergia Butler, 2005, Hypsilophodon, D. altus). Both the proximal and distal ends are broader than the midshaft. Slightly distal to the mid-length of the shaft, the metatarsal is slightly deflected laterally and thus diverges slightly from metatarsal III. This results in a gap between metatarsal III and IV in their distal third, although the expansion of the distal condyles of metatarsals III and IV close this gap again. The distal part of the shaft of metatarsal IV is slightly sigmoidal and the articular surface of the distal condyle faces distolaterally, a feature that resembles the condition in Abrictosaurus, but not in Heterodontosaurus (Fig. 3.1-3.4, 3.8). The anteroplantar depth of the distal condyle is smaller than its lateromedial width. However, the width of the distal condyle is larger than that of the other metatarsals.

Although the articular surfaces of the distal ends of metatarsals II, III and IV face slightly medially or laterally, the slender metatarsals diverge distally only slightly from each other along their entire length, resembling the condition of small cursorial ornithischian dinosaurs (e.g., Heterodontosaurus [Santa Luca, 1980], Lesothosaurus [Sereno, 1991], Gasparinisaura [Coria and Salgado, 1996; Salgado et al., 1997], Tianyulong [Zheng et al., 2009], Agilisaurus [Peng, 1992]). In contrast, larger ornithopods have more distally diverging metatarsals (i.e., dryosaurids [Galton, 1981], Tenontosaurus [Ostrom, 1970]) and the metatarsus is not as compactly arranged (e.g., Thescelosaurus [Gilmore, 1913], Camptosaurus [Galton and Powell, 1980], ceratopsids [Dodson et al., 2004], thyreophorans [Galton and Upchurch, 2004b; Vickaryous et al., 2004], hadrosaurs [Horner et al., 2004]). In these more graviportal taxa, the metatarsals are more robust and proportionally shorter (see Coombs, 1978).

The lateromedial width of distal condyles in metatarsals II and IV is larger than their anteroplantar depth, a feature that is present in basal ornithischian taxa, such as Pisanosaurus Casamiquela, 1967 (PVL 2577, M.G.B. personal observation) and heterodontosaurids (Fruitadens [Butler et al., 2012], Heterodontosaurus [SAM-PK-K1332]), and also in Stormbergia (SAM-PK-K1105), basal ceratopsids (e.g., Longrich, 2010), and psittacosaurids (e.g., You and Dodson, 2004). Furthermore, this is a widespread condition in basal dinosauriforms and basal saurischians as Marasuchus lilloensis (Romer, 1972) (Sereno and Arcucci, 1994), Herrerasaurus Reig, 1963 (Novas, 1993), and basal sauropodomorphs (Galton and Upchurch, 2004a) such as Coloradisaurus brevis (Bonaparte, 1978) (Apaldetti and Martinez, 2010; Apaldetti et al., 2013). However, the lateromedial width is smaller than or subequal to the anteroplantar depth in these distal condyles in many ornithischians, such as Lesothosaurus (SAM-PK-K426), 
Hypsilophodon (Galton, 1974b), Dysalotosaurus lettowvorbecki (MBR 1540, 1541 and 1542, [Galton, 1981]), Othnielosaurus (YPM 1882), Scelidosaurus Owen, 1861 (NHMUK R1111) and hadrosaurs (Horner et al., 2004). However, a return to the condition in basal groups is observed in pachycephalosaurids (i.e., Perle et al., 1982; Maryanska and Osmólska, 1974) and other more derived and usually larger ornithischians, such as thyreophorans (i.e. Gilmore, 1914; Carpenter, 2004), and ceratopsids (Dodson et al., 2004). This subject is discussed further below. Finally, the presence of coossified tarsometatarsi is an uncommon feature for an ornithischian, but its presence in Heterodontosaurus supports the affinities of MPEF-PV 3826 with Heterodontosauridae (Santa Luca, 1980; Sereno, 2012).

Phalanges.-All phalanges were disarticulated but closely associated with the metatarsi. There are 19 different phalanges, including four unguals (see Supplemental Data 4 and Supplemental Data 5). All non-ungual phalanges are relatively slender and elongated but vary in their proportions, with some being shorter than others in relation to their lateromedial width. These variations in proportion are interpreted as reflecting the different positions within each digit (Fig. 4.1-4.3, 4.7-4.10). All non-ungual phalanges have a subtriangular to subrhomboidal concavity on their plantar surface, located at the proximal end. These phalanges have an inverted V-shaped distal ginglymoidal facet, in which the condyles are more bulbous plantarly than dorsally and are divided by a deep groove, which matches the proximal, subtriangular articular surface. The lateral and medial ligament pits are deep and well developed in the distal phalanges, as in Tianyulong (Sereno, 2012, fig. 28), other heterodontosaurids (Butler et al., 2012; Sereno, 2012), and bipedal ornithopods (Norman et al., 2004).

The more robust phalanges (proximal width/proximodistal length ratio varying between 0.296 and 0.467 ) are straight and have a gently concave proximal articular surface. The proximal and distal articular ends are either aligned with each other (phalanges associated with digit III) or slightly twisted along the proximodistal axis of the phalanx (phalanges referred to the other digits). These phalanges have a deep extensor pit above the distal condyle (Fig. 4.1, 4.7), which is absent or poorly developed on the slender-type phalanges (see below). The presence of deep extensor pits with well-marked limits contrasts with the condition in other bipedal ornithischians, such as Gasparinisaura and Anabisetia, while presenting a similar condition than Othnielosaurus and Heterodontosaurus, but present in all proximal phalanges (M.G.B. personal observation). The proximal concavity on the plantar surface of these phalanges is subtriangular and the elements have a triangular cross section at their midshaft.

The more slender phalanges have a range of proximal width/proximodistal length ratio that varies between 0.259 and 0.321 (Fig. 4.7-4.9) and are interpreted as non-proximal phalanges. These phalanges have a deeper proximal articular facet, which is bordered dorsally by a proximodorsal lip (Fig. 4.7-4.9). The distal articular surface of these phalanges allows a range of motion that is greater than in the proximal phalanges (approximately $260^{\circ}$ and $195^{\circ}$, respectively), as seen in lateral view. The dorsal surface of the proximodorsal lip extends along the shaft as a wide dorsal crest that gradually decreases in prominence and disappears by the midshaft, where the phalanges are sub-circular in cross section. These phalanges have a deep concavity in the proximal region of their plantar surface, which is longer and sub-rhomboidal in comparison with the triangular depressions of the proximal phalanges. The more slender phalanges lack a distal extensor pit.

Two of the ungual phalanges have a dorsally convex and ventrally concave distal (claw) portion preserved. One of these elements is long and slender, while the other is distally incomplete (Fig. 4.5-4.6). The two other phalanges have only their proximal portion preserved (eg., Fig. 4.4). The ungual phalanges comprise a blocky proximal half and a thin and arched distal half (Fig. 4.4-4.6). The proximal articular surface is deep and sub-circular, and its margins project slightly laterally and medially with respect to the rest of the ungual. In the most complete ungual, a long and wide collateral groove extends distally from the dorsal midpoint of the phalanx but fails to reach the distal tip of the ungual. The dorsal and plantar margins of this groove are not well defined. The distal region of the ungual is ventrally rounded, with a subcircular to ellipsoidal cross section, and lacks lateral projections of the margins plantar to the collateral groove. This type of ungual phalanx resembles that of Tianyulong, but differs from the ventrally flat, arrowshaped unguals with laterally elongated margins and a subtriangular transversal section of Heterodontosaurus, Anabisetia, Hypsilophodon, and other bipedal ornithischians. One particular feature of MPEF-PV 3826 is that the flexor tubercle is not placed directly ventral to the articular surface but is displaced distally, indicating the presence of flexor ligaments with larger leverage, as inferred for some theropod dinosaurs (Ostrom, 1969). The flexor tubercle and the articular surface are separated by a lateromedially convex and anteroposteriorly flat plantar surface of the ungual, which accounts for approximately $45 \%$ of the total length of the bone. The presence of a large and ventrally projected flexor tubercle is a feature shared with the small-bodied Tianyulong, but is a condition absent in Heterodontosaurus and derived ornithopods, having a small and poorly developed flexor tubercle or completely absent (which have the claw morphology mentioned above or hoof-like unguals). Comparing the only complete ungual of MPEF-PV 3826 with those of Tianyulong, the recurved portion of the ungual is shorter relative to the rest of the element and the flexor tubercle is smaller and less displaced distally in the Chinese taxon (Fig. 4.2).

Reconstruction of the pes.-All the available phalanges were disarticulated, but their position within the pes can be inferred on the basis of their relative size and morphology, as well as based on comparison with Heterodontosaurus and Tianyulong (Fig. 5). The pedal phalangeal formula is assumed to be 2-3-4-5-0, the common condition in basal dinosaurs (basal Saurischia [Langer, 2004], basal Theropoda [Weishampel et al., 2004], basal Sauropodomorpha [Galton and Upchurch, 2004a]), including most basal and bipedal ornithischians (i.e., Heterodontosaurus, Tianyulong, Lesothosaurus, Eocursor Butler, Smith and Norman, 2007, Agilisaurus, Scutellosaurus Colbert, 1981).

The more robust and ventrally flat phalanges with a welldeveloped extensor pit and a limited condylar surface are interpreted as proximal phalanges that articulate with the 
metatarsals. Four phalanges have these features, but they are slightly different from each other, so they are interpreted as the first phalanx of each digit. One of these phalanges has a proximal articulation that is laterally offset from the shaft and is proximodistally shorter than the other elements. Its relative size resembles that of phalanx I.1 of other heterodontosaurids, and we have therefore identified it as the first phalanx of digit I (Fig. 5.4). Among the remaining proximal phalanges, one element has a straight shaft with aligned proximal and distal articular surfaces, as in phalanx III.1 of other bipedal ornithischians (e.g., Heterodontosaurus, Anabisetia, Gasparinisaura). This phalanx also has a proximodorsal process (Fig. 4.10-4.12), a feature present in phalanx III.1 in Heterodontosaurus (Santa Luca, 1980; Butler et al., 2012), but unknown in other heterodontosaurids with preserved hind limb material (i.e., Fruitadens, Tianyulong, and Abrictosaurus). Based on these characters we have identified this element as the first phalanx of digit III. The two remaining proximal phalanges were identified based on their relative length, given that in Heterodontosaurus and Tianyulong phalanx II.1 is longer than the phalanx IV.1 (Fig. 5).

All other non-terminal phalanges (11 elements) are interpreted to come from more distal positions (Fig. 5.3-5.4). Among these slender phalanges, four elements have a lateromedially and anteroplantarly wider proximal articular surface than the other phalanges. Two of these are identical to each other and interpreted as the same element of the left and right pes (phalanx IV.2; see below), whereas the two others differ in their relative length and width as well as the shape of the distal articular surface. One of the latter phalanges has a markedly narrow distal articular surface that likely articulated with an ungual, which is expected for phalanx II.2. The other three phalanges have a broader distal end, with the repeated elements being proportionately narrower at their distal end than the remaining third phalanx. Based on comparisons with other heterodontosaurids, and considering their proportions and the relative development of the distal articular surface, we identify the repeated elements as IV.2 and the distally broader phalanx as III.2 (Fig. 5).

The remaining seven phalanges include six complete elements and one phalanx that is too fragmentary to be identified. The six complete phalanges can be separated into three pairs of identical elements (in terms of their proportions and morphology). These phalanges have a lateromedially and dorsoplantarly smaller proximal articular facet than the previous elements and a narrower distal articular surface (suitable for the articulation of another slender phalanx or ungual phalanges). The pair of phalanges with the narrowest distal articular surface and a deep intercondylar groove is interpreted as phalanges IV.4 of either foot. Of the two other pairs of phalanges, the longer and proximally broader elements are interpreted as III.3, whereas the relatively shorter elements with a narrower proximal articular facet are interpreted as IV.3 (Fig. 5).

The foot was clearly digitigrade. The orientation of the distal condyles of the metatarsals and the associated phalanges indicate that digit III was aligned with the pedal axis, as in Heterodontosaurus (Santa Luca, 1980). Based on the interpretation presented above, the complete digit I would be longer than metatarsal II, and digit III would be the longest in the pes, as in Heterodontosaurus and Tianyulong (Sereno, 2012).
The pes of MPEF-PV 3826 has slightly longer pedal digits II, III, and IV (in proportion to the metatarsus) than other heterodontosaurids (Fig. 5). In comparison with other bipedal ornithischian, the preserved phalanges furthermore seem to be longer and proportionately more slender. Based on the interpretation of phalangeal identity presented above, the distalmost non-ungual phalanges are longer than the immediately preceding elements (Fig. 5.3-5.4). This feature is unusual and differs from the generalized condition of the pes in cursorial taxa, which have proportionately longer metatarsals and phalanges that become progressively shorter toward more distal positions (Coombs, 1978; Hopson, 2001).

\section{Histological analysis}

To identify the ontogenetic stage of MPEF-PV 3826, a thin section of the mid-distal portion of the shaft of the left metatarsal IV was taken and analyzed. The cross section reveals a thick compact cortex that encircles a free medullary cavity (Fig. 6, color version presented in Supplementary Data 6). The perimedullary cortex consists of an inner circumferential layer (ICL sensu Chinsamy-Turan, 2005) of endosteal lamellar tissue, which is strongly birefringent under polarized light. This tissue has numerous lamellae that are concentrically deposited and enclose strongly flattened osteocyte lacunae. The middle and outer cortex are formed by primary tissue of woven fibered matrix, mostly mono-refringent under polarized light. The primary matrix is vascularized by numerous longitudinally oriented canals. Many of these canals have a thin band of lamellar tissue internally, indicating that they are primary osteons. The presence of primary osteons embedded in a woven matrix identifies the primary tissue as a fibrolamellar tissue. The fibrolamellar tissue (primary) is clearly separated from the ICL (secondary tissue) by a resorption line. The primary tissue has a rather homogeneous aspect throughout the cortex, and becomes only slightly birefringent in some regions of the outer cortex. This slightly birefringence in the outer region is interpreted as a minor change of the fiber arrangement from woven fibered to a more parallel fibered tissue. There are no visible growth marks in the cortical tissue. Secondary (Haversian) osteons are also absent in the sampled bone. The sub-periosteal surface seems to be smooth, indicating that the externally opening vascular canals were closed.

Available information of comparable thin sections of other ornithischian dinosaurs is limited. Although Horner et al. (2009) sectioned several bones (including metatarsals) of various ontogenetical stages of Orodromeus makelai, Dryosaurus altus, and Tenontosaurus tilletti Ostrom, 1970, only femora and tibiae sections were discussed. Similarly, histological sections of metatarsals were performed but not described in Dysalothosaurus lettowvorbecki Virchow, 1919 and in several other studies on the bone histology of ornithischian dinosaurs (e.g., Chinsamy, 1995; Hayashi et al., 2009; Woodward et al., 2011; Hübner, 2012; Werning, 2012; Redelstorff et al., 2013). The thin sections of the metatarsals of Gasparinisaura cincosaltensis (Cerda and Chinsamy, 2012) and Maiasaura Horner and Makela, 1979 (Horner et al., 2000) are the only available source for direct comparison. 
The juvenile stages of Maiasaura already show Haversian tissue in the massive primary fibrolamellar cortex, which continues to develop from the inner region of the cortex toward the external region during ontogeny. The secondary bone tissue in the medullary cavity and the endosteal margin around it also start to grow at early juvenile stages. This type of secondary tissue development could not be identified in MPEF-PV 3826, nor could any sign of bone absorption and reconstruction or Haversian tissue development. The Harvesian tissue growing during the first stages of ontogeny might respond to the elevated growth rates and/or (more probably) the need to accomplish mechanical and support requirements. Because MPEF-PV 3826 and Maiasaura are significantly different in several respects (e.g., size, locomotory habits) and they are also phylogenetically distant, their histological differences are not unexpected. The available metatarsal thin sections of Gasparinisaura, a smallsized ornithischian, are more similar in terms of the histological features. Gasparinisauria has a transition from endosteal lamellar tissue surrounding the medullary cavity, via compacted coarse cancellous and fibrolamellar, to parallel-fibered bone in the shaft of metatarsal IV. Similarly, in MPEF-PV 3826 there is endosteal lamellar tissue covering the medullary cavity and fibrolamellar bone in the cortex (indicating a high growth rate; Francillon-Vieillot et al., 1990; Reid, 1996; Chinsamy-Turan, 2005), but there are no lines of arrested growth (LAGs), no secondary Haversian tissue, or secondary osteons in this portion.

\section{Morphometrics of metatarsals in bipedal ornithischians}

Here we use a cluster analysis as a comparative tool, to test the overall similarity of the proportions of the metatarsals of MPEFPV 3826 to other ornithischian taxa with bipedal locomotion. This analysis has no systematic purposes, as the phenetic similarity is not necessarily indicative of phylogenetic affinity (Farris, 1981). We perform a cluster analysis, using the average linkage as a distance measure between specimens and a hierarchical classification algorithm to maximize the differences between clusters in relation to the variation within each cluster. In the results, the cophenetic correlation or coefficient of linear correlation (of Pearson) is given, which refers to the approximation of the distance matrix to an ultrametric matrix based on the proximity criterion taken. This coefficient is equal to 1 if both matrices are proportional.

We use the proportional length of metatarsals I, II, and IV compared to the length of metatarsal III as variables that can be scored in MPEF-PV 3826 and a broad sample of bipedal ornithischian taxa. Metatarsal $\mathrm{V}$ is not included in this analysis because of the highly variable length and presence among ornithischians which might influence the resulting clusters. The metric measurements are presented in Supplementary Data 7, whereas the resulting euclidean and ultrametric matrix are presented in Supplementary Data 8 and 9, respectively.

Results.-The results obtained in the hierarchical cluster analysis places MPEF-PV 3826 together with heterodontosaurids, which is recovered as a unique and well differentiated cluster
(Fig. 7). In general terms, this analysis clusters heterodontosaurids with other small bipedal taxa, such as basal ornithopods (e.g., Anabisetia, Hypsilophodon, Thescelosaurus, Othnielosaurus, Agilisaurus) and basal ornithischians (e.g., Lesothosaurus, Stormbergia). However, other bipedal taxa, such as dryosaurids and Gasparinisaura, are placed outside this cluster. The high cophenetic correlation coefficient $(\mathrm{CCC}=0.946)$ indicates an overall good correlation between the distance and the ultrametric matrices.

The recovery of MPEF-PV 3826 within the heterodontosaurid cluster reflects the overall similarity in metatarsal proportions. Furthermore, the proportions of the metatarsus within Heterodontosauridae are relatively homogeneous, as represented by the small Euclidean distances between taxa (in comparison with those of other bipedal ornithischians). Given that all included taxa in this analysis are small bipedal species which probably share similar locomotory biomechanics, it is likely that the different clusters found for heterodontosaurids and basal ornithopods reflect some phylogenetic signal. The variability in the proportions of the metatarsals of these taxa were incorporated in the phylogenetic analysis (as continuous characters, given the nature of their variation; see below).

\section{Phylogenetic analysis}

The phylogenetic affinities of MPEF-PV 3826 were tested using a modified version of the data matrix originally compiled by Butler et al. (2008). We integrated the subsequent modifications made by several authors to this original dataset (Zheng et al., 2009; Butler et al., 2010, 2011; Pol et al., 2011; Han et al., 2012), the new information provided by Sereno (2012) on heterodontosaurids, and added new data.

Subsequent modifications of the dataset of Butler et al. (2008) have added taxa (e.g., Fruitadens haagarorum, Tianyulong confuciusi, Eocursor parvus Butler, Smith and Norman, 2007, Yinlong downsii $\mathrm{Xu}$, Forster, Clark and Mo, 2006 [Butler et al., 2010, 2011]), re-scored cells for some taxa (e.g., Wannanosaurus yansiensis Hou, 1977, Micropachycephalosaurus hongtuyanensis Dong, 1978, and Stenopelix valdensis Von Meyer, 1857, following Butler et al., 2011; and Jeholosaurus shanyuanensis Xu, Wang, and You, 2000a, following Han et al., 2012) and added new characters. Some of these papers were published almost simultaneously and therefore we have here integrated all of these changes.

We followed the recent anatomical interpretations presented by Sereno (2012) in his comprehensive review of Heterodontosauridae and incorporated these into the updated version of the dataset of Butler et al. (2008). These include the addition of Pegomastax to the data matrix, a re-scoring of most heterodontosaurids based on the new anatomical information, and the addition of 18 new characters included in the heterodontosaurid data matrix of Sereno (2012). The scores for Manidens condorensis were based on Pol et al. (2011) and Sereno (2012), with codings for the new characters being added. Only two characters were re-scored in Jeholosaurus based on the recent detailed description by Han et al. (2012). All changes are detailed in Supplementary Data 10.

Finally, as our phenetic analysis found informative variation in the metatarsus (see above), which may characterize heterodontosaurids among ornithischian dinosaurs, we have 


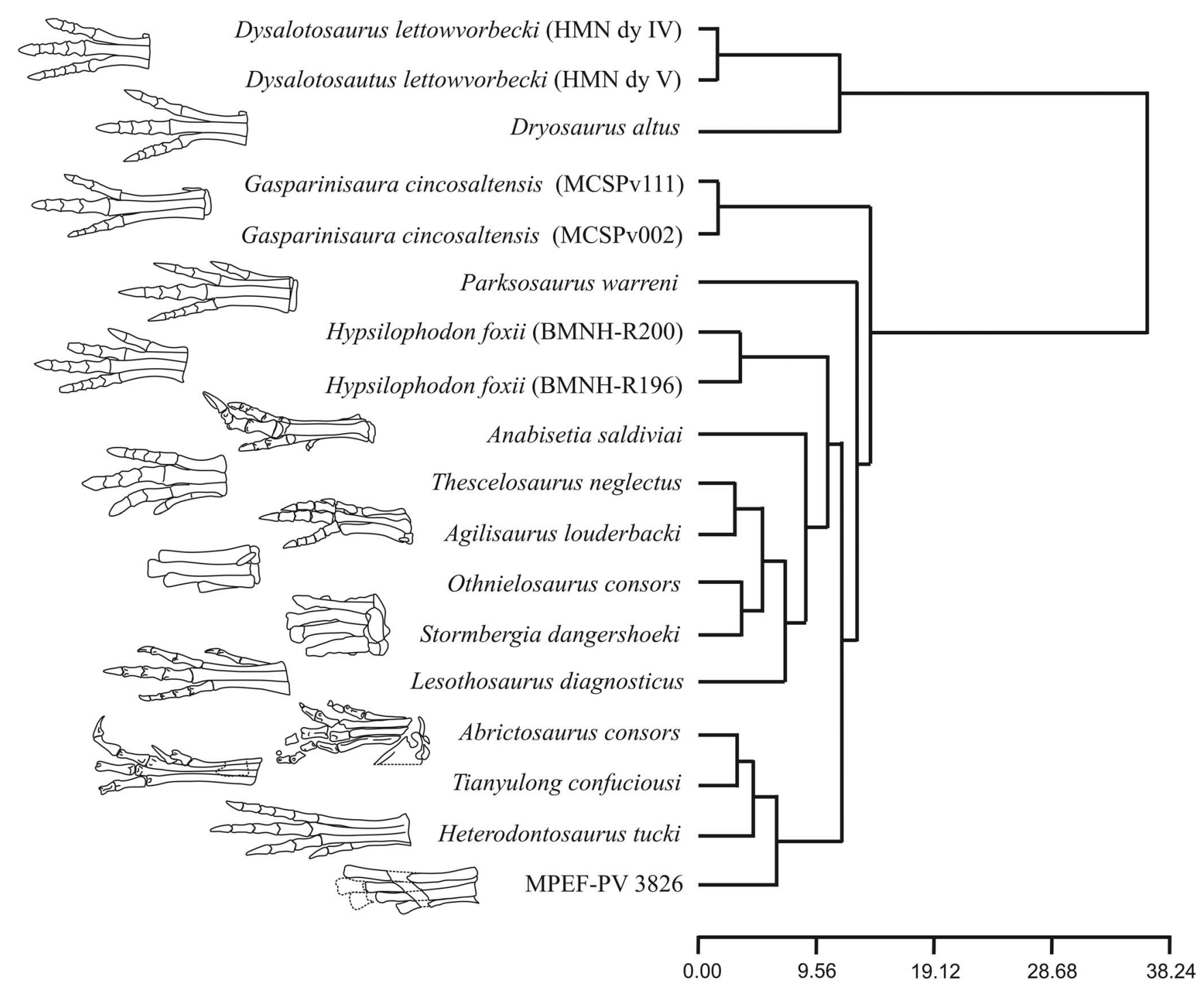

Figure 7. Cluster analysis results, including schematic representation of the pes of included taxa.

added 11 new characters to the data matrix (three continuous and eight discrete characters) and modified the definition of character 209 (Butler et al., 2008), adding a new character state. The new characters, as well as the modified character 209 , are discussed below. The final version of the data matrix includes 53 taxa and 259 characters. These modifications aim to test the affinities of the specimen MPEF-PV 3826 with Heterodontosauridae within the context of ornithischian dinosaurs.

Character descriptions: continuous characters.-The results of the cluster analysis indicate that there are differences in metatarsal proportions (compared to metatarsal III) that group heterodontosaurids and basal ornithischians in different clusters, despite the fact that these species share similar size and locomotor capabilities (Fig. 8.5). The following characters capture linear morphometric ratios that vary continuously among taxa and lack clearly defined gaps in their distribution. They were therefore treated as continuous characters in the phylogenetic analysis (Fig. 8.5), and were normalized to range between 0 and 1 .
1: Metatarsal I/metatarsal III length ratio.-The importance of the lateral and medial digits tends to diminish through the evolution of Ornithopoda, as indicated by the reduction and finally complete loss of medial and lateral metatarsals I and V. Several basal ornithopods lack phalanges in the reduced digit $\mathrm{V}$, but only Gasparinisaura and Orodromeus also lack phalanges in digit I among non-iguanodontian ornithopods (Norman et al., 2004). Furthermore, complete loss of the phalanges in digits I and V is also documented in several basal iguanodontians (Dryosaurus altus, Iguanodon bernissartensis Boulenger, 1881, Mantellisaurus atherfieldensis Hooley, 1925 [Norman, 2004]), and hadrosaurs, which also lack metatarsals I and V (Horner et al., 2004). In basal ornithischians and ornithopods, metatarsal I is present and its length in relation to metatarsal III varies markedly, with values ranging between 0.10 and 0.68 . However, this ratio is relatively homogeneous among heterodontosaurids $(0.55-0.58)$. This contrasts with the situation in ornithopods, in which the progressive reduction of metatarsals I and $\mathrm{V}$ results in a large interval of ratios. Thus, heterodontosaurids seem to be anatomically conservative in this respect. 

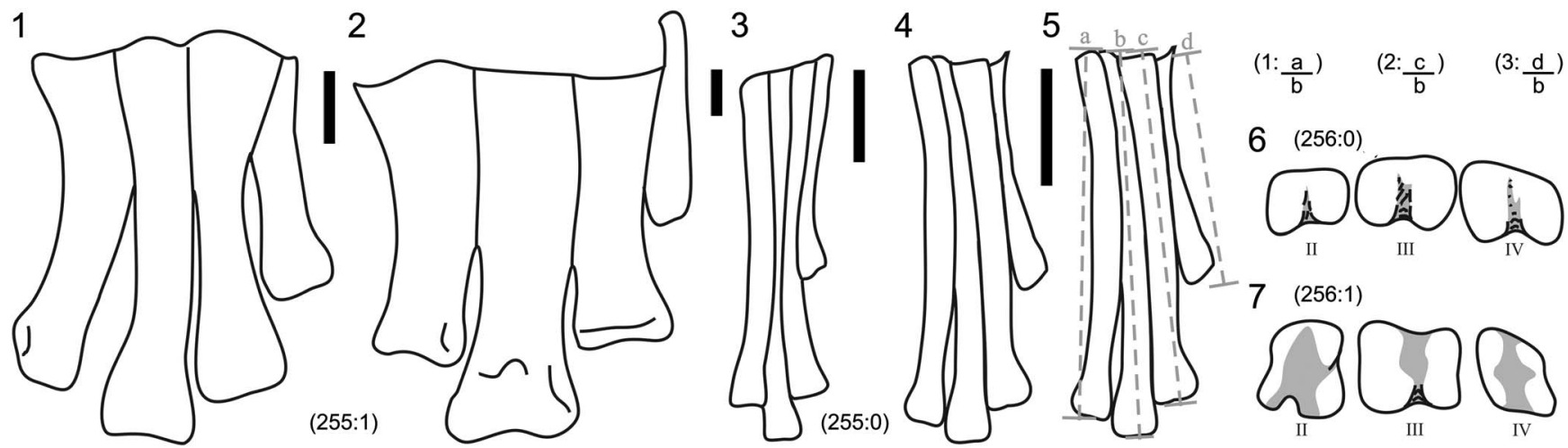

$6 \quad(256: 0)$

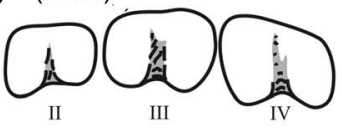

$7 \quad(256: 1)$

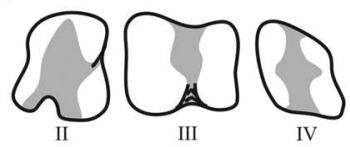

Figure 8. Schematic line drawings representing the new characters described: (1) Tenontosaurus tilletti, modified from Galton (1974a); (2) Camptosaurus dispar, modified from Galton (1974a); (3) Tianyulong confuciusi, based on photographs in Zheng et al. (2009; supplementary material); (4) MPEF-PV 3826, left metatarsals; (5) the same as (4) but outlining the measurements taken to calculate the proportions for characters (1-3); (6, 7) schematic line drawing of distal view of condyles of metatarsals II-IV of MPEF-PV 3826 and Hipsilophodon foxii Huxley, 1869 (modified from Galton, 1974b). The numbers represent the character and state figured as (ch:st). Scale bars equal $1 \mathrm{~cm}$.

2: Metatarsal II/metatarsal III length ratio.-This ratio varies between 0.86 and 0.9 among heterodontosaurids. Among the other species there are two patterns. While some small-bodied basal ornithopods show smaller values of length ratio (i.e., Hypsilophodon, Anabisetia, Othnielosaurus, Stormbergia with less than 0.83 ), others show higher values of length ratio (as Gasparinisaura, with more than 0.9), although most of the considered species at the cluster analysis show similar values than heterodontosaurids. Among other ornithischian lineages, the acquisition of columnar limbs in the heavy-bodied thyreophorans and the retention of several adaptations to a subcursorial locomotion in large cerapodans (Coombs, 1978) result in metatarsal elements that are subequal in length and show a marked symmetry on both sides of digit III. In these groups, the decrease in length of all digits and the reduction of lateral digits lead to a robust pes with a large surface for support in relation to the length of the metapodium. The difference in ratio between small and large ornithischians is thus certainly related to an increase in body size (Coombs, 1978).

3: Metatarsal IV/metatarsal III length ratio.-As in the former character, bipedal cursorial ornithischians have lower ratios than large-bodied taxa. However, in comparison with metatarsal II, metatarsal IV is usually slightly shorter in larger ornithischians, whereas it is similar (or longer) than metatarsal II in smaller ornithischians.

Character description: discrete characters.-The only characters described here are those modified from the original matrix of Butler et al. (2008: character 209) and eight new characters (Figs. 8-9).

212: Medial distal tarsal.-(0) articulates with metatarsal III only; (1) articulates with metatarsals II and III; (2) articulates with metatarsals I, II and III. (modified from character 209 of Butler et al. [2008] by adding character state 2). The distal tarsals of Heterodontosaurus tucki were first described as three fused elements, which would be an unusual condition among ornithopods, which commonly retain only two elements, and to which clade this species was referred at that time (Santa Luca, 1980; Norman et al., 2004). In this interpretation, distal tarsal 1 was said to contact metatarsals I and II, distal tarsal 2 contacted metatarsal III, and distal tarsal 3 contacted metatarsal IV (also in Norman et al., 2004). Butler et al. (2010) scored Heterodontosaurus as having the articulation of the medial distal tarsal with metatarsal III only, and Zheng et al. (2009) scored the same character state for the heterodontosaurid Tianyulong (Zheng et al., 2009). However, Sereno (2012) argued that there are only two distal tarsals in the right pes of Heterodontosaurus (SAMPK-K1332), and that the putative contact between distal tarsal 1 and 2 (Santa Luca, 1980) is indeed a crack. Therefore, he concluded that this taxon has the common condition of only two distal tarsals (as in Tianyulong). Based on this interpretation, Heterodontosaurus and Tianyulong are here regarded as having an enlarged medial distal tarsal that articulates with metatarsals I, II and III. This character state also is present in MPEF-PV 3826, and might be a common feature among heterodontosaurids.

252 (new character).-Metatarsals proximally coossified to each other (in sub-adult to adult specimens): (0) absent; (1) present. Santa Luca (1980) considered the metatarsals of Heterodontosaurus to be closely appressed to each other (a common condition among ornithischians [Norman et al., 2004]). However, Sereno (2012) argued that the metatarsals were in fact fused, not only in Heterodontosaurus but also in Tianyulong. Furthermore, he interpreted the absence of a coossified tarsometatarsus and the absence fused metatarsals in Abrictosaurus (NHMUK RU B54) to reflect the juvenile ontogenetic stage of this specimen. In MPEF-PV 3826 the metatarsals are coossified proximally.

253 (new character).-Presence of a tarsometatarsus, with at least metatarsals I-III being partially or totally coossified with medial distal tarsal (in sub-adult to adult specimens): (0) absent; (1) present. The presence of a tarsometatarsus (fusion of metatarsals and distal tarsals) in Heterodontosaurus was regarded as a distinctive feature among ornithischian dinosaurs (Santa Luca, 1980). Although the lateral distal tarsal is missing 

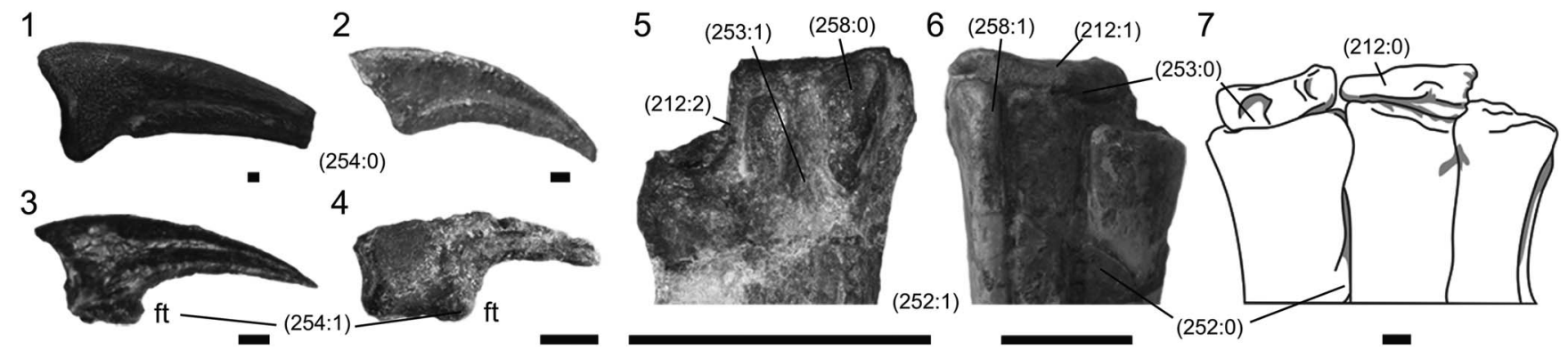

Figure 9. Photographs illustrating new characters. (1) Lateral view of ungual phalanx of digit I of Othnielosaurus consors YMP 1882, photo courtesy of Dr. I. Diaz Martinez; (2) Heterodontosaurus tucki SAM 1332, ungual phalanx of digit IV; (3) Tianyulong confuciousi STMN 26-3, ungual phalanx of digit III (Zheng et al., 2009, supplementary material); (4) most complete ungual phalanx of MPEF-PV 3826; (5) proximoplantar view of medial distal tarsal and proximal metatarsals of MPEF-PV 3826; (6) proximoplantar view of medial distal tarsal and metatarsals of Gasparinisaura cincosaltensis (MUCPv-208); (7) anteroproximal view of medial and lateral tarsals of Camptosaurus dispar, modified from Gilmore (1909). ft, flexor tubercle. The numbers represent the character and state figured (ch:st). Scale bars equal $1 \mathrm{~mm}$ in (1-4) and $1 \mathrm{~cm}$ in (5-7).

in Tianyulong, the medial distal tarsal is completely fused to the metatarsals also in this taxon (Sereno, 2012). In MPEF-PV 3826 , the lateral distal tarsal is also missing, but the medial distal tarsal is fused to metatarsals I-III. The coossification of the lateral distal tarsal and metatarsal IV is highly likely in MPEF-PV 3826 (see above), but the character definition is here restricted to the medial distal tarsal, given that it is the only element preserved in both Tianyulong and MPEF-PV 3826. The character was coded as uncertain in Abrictosaurus, due to the immature ontogenetic stage of the type specimen of this taxon. A tarsometatarsus is also present in some theropods (some coelophysoids [Tykoski and Rowe, 2004], oviraptorids [Olmólska et al., 2004], troodontids [Makovicky and Norell, 2004], dromaeosaurids [Norell and Makovicky, 2004] and birds [Padian, 2004]), but in heterodontosaurids it does not reach the degree of coossification as observed in some of these lineages.

254 (new character).- - Ventral flexor tubercle in pedal unguals: (0) absent or developed as a low mound near the articular surface of the ungual phalanx; (1) present, well-developed protuberant process that is displaced distally, resulting in a flat ventral space between the tubercle and the articular surface. Although the presence of a flexor tubercle in pedal ungual phalanges is a widespread feature among archosaurs and plantarly prominent and rounded flexor tubercles commonly seen among Theropoda, the presence of a plantarly prominent distally displaced flexor tubercle is an unreported feature within Ornithischia. However, this feature is present in both MPEF-PV 3826 and Tianyulong (IVPP V17090, Sereno, 2012, fig 28-29; STMN 26-3, Zheng et al., 2009, supplementary material). As in some extant birds, MPEF-PV 3826 has a highly developed flexor tubercle, which is also present but less pronounced in Tianyulong (if compared to the total length of the ungual). This phylogenetic character might also be informative from an ecological point of view, as it was interpreted as an acquisition to assist grasping in bipedal cursorial dinosaurs with small forelimbs (Sereno, 2012).

255 (new character).- Subarctometatarsalian condition (sensu White, 2009): (0) absent, no proximal overlapping of metatarsals II and IV over metatarsal III and metatarsal III being wider lateromedially than the other metatarsals in anterior view (representing more than $30 \%$ of total width of the shaft in anterior view); (1) incipient subarctometatarsalian condition, with the proximal part of metatarsal III being partially covered by metatarsals II and IV, and the lateromedial width of metatarsal III is notably less than that of the other metatarsals (being less than $30 \%$ of the width of the shaft proximally and until the mid-length in anterior view). In the subarctometatarsalian condition the proximal end of metatarsal III is equally visible in both anterior and plantar views. In plantar view, metatarsal III is visible along its entire length. Proximally, metatarsal III is lateromedially pinched between metatarsals II and IV, a feature that extends at least down to the midshaft, while the distal end of metatarsal III broadens (White, 2009). This condition was described for the basal tyrannosaurid Dilong paradoxus Xu, Norell, Kuang, Wang, Zhao, and Jia, 2004 (IVPP V11579). The specimen MPEF-PV 3826 has an incipient subarctometatarsal condition, which is markedly different from the generalized ornithischian morphology. The metatarsals are tightly packed, and metatarsal III is partially covered by metatarsals II and IV along its proximal half in both anterior and plantar views. Metatarsal III has a trapezoidal cross section (with the narrower end pointing plantarly, instead of being wedge-shaped as in Dilong). This condition is also present in Heterodontosaurus (SAM-PK-K 1332), and might be present in Tianyulong (specimen STMN 26-3), for which no anterior view has been published, but mentatarsal III is characteristically pinched in plantar view. The condition in Abrictosaurus is unclear due to the supposedly juvenile stage of the type and only known specimen (Sereno, 2012). All other bipedal ornithischian dinosaurs have tightly packed, cylindrical metatarsals without a pinched shaft (e.g., Lesothosaurus, Stormbergia, Scutellosaurus, basal Ornithopoda) or lateromedially expanded metatarsals that are subequal in length and adapted for graviportal locomotion in heavier and often quadrupedal animals, as mentioned above (thyreophorans, more derived ornithopods and hadrosaurs, ceratopsids).

256 (new character). - Metatarsals II and IV, mediolateral width of articular condyles in distal view: (0) larger than anteroplantar height; (1) equal to or smaller than anteroplantar height. The lateromedial width is larger than the anteroplantar height in 
metatarsals II and IV in several basal dinosaur groups (e.g., basal sauropodomorphs, basal saurischians, heterodontosaurids) and the robust metatarsals of more heavy-bodied ornithischians (ceratopsids, thyreophorans). This contrast with the proportionately narrow distal ends of metatarsals II and IV in cursorial ornithopods (i.e., Dysalotosaurus, Hypsilophodon, Othnielosaurus, Parksosaurus warreni Sternberg, 1937 [=Thescelosaurus warreni Parks, 1926], Lesothosaurus, Gasparinisaura, Anabisetia), as well as in large ornithopods, iguanodontids and hadrosaurs. In these species, the anteroplantar height is larger than the lateromedial width in the distal ends of metatarsals II and IV. The presence of lateromedially wider condylar surfaces in heterodontosaurids can be considered to be the plesiomorphic condition of this character that remained unchanged in heterodontosaurids throughout most of the Mesozoic.

257 (new character).-Extensor pits in distal ends of proximal phalanges of pedal digits II-IV: (0) absent; (1) present. This character was discussed by Sereno (1986), who proposed it as a synapomorphy of Heterodontosauridae, and briefly mentioned by Butler et al. (2012), but it has not been included in a phylogenetic analyses. We include this feature as a phylogenetic character.

258 (new character).- "Hypotarsal-like" proximodistally oriented process on the plantar surface of the medial distal tarsal, above metatarsal II: (0) absent; (1) present. Santa Luca (1980, fig. 10C) described a proximodistally oriented process or flange exposed plantarly in tarsal 1 (medial distal tarsal sensu Sereno, 2012) in Heterodontosaurus. This process was argued to serve for the attachment of flexor tendons of the pedal digits, as it is the case in the hypotarsal ridge of extant birds (Santa Luca, 1980; Norman et al., 2004). The plantar side of both pedes is exposed in the holotype specimen of Tianyulong (STMN 26-3), showing the same vertically oriented process above metatarsal II (Zheng et al., 2009; supplementary material). Finally, MPEFPV 3826 also shows this hypotarsal ridge (Fig. 2.3-2.6, 3.1-3.2). This feature cannot be scored for Fruitadens and Abrictosaurus, and it has not been described in any other ornithischian. The only possible exception was noted by Han et al. (2012), who described an L-shaped medial distal tarsal in Jeholosaurus shangyuanensis (horizontal and vertical portion of the "L" corresponding to distal tarsals 1 and 2, respectively), with a proximally placed ridge marking the suture line between the fused tarsals. A similar condition may also be present in Orodromeus makelai, as described by Scheetz (1999). In these two species, this particular tarsal seems to expose a protuberant structure plantarly (see Han et al., 2012, fig. 12), resulting in an L-shaped medial distal tarsal in proximal view (with the horizontal portion of the $\mathrm{L}$ being formed by this structure), but there is no further description of this structure. The condition in Orodromeus and Jeholosaurus might be morphologically and functionally comparable to the hypotarsal-like process of the medial distal tarsal in heterodontosaurids, but the lack of an a detailed description, including the orientation and development of this process, does not allow to score character state 1 for these two species with certainty, so they were scored as ambiguous in the data matrix.
259 (new character).-Extensor process located dorsally at the proximal end of the first phalanx of pedal digit III: (0) absent; (1) present. The presence of an extensor process above the proximal articular surface of pedal phalanx III.1 was described for Heterodontosaurus by Santa Luca (1980). This process can also be recognized in MPEF-PV 3826 (Fig. 4.10-4.12), and is subtly developed in Abrictosaurus (NHMUK RU B54; Sereno, 2012, fig. 37). The presence of such a process cannot be determined for Tianyulong (specimen IVPP V17090, Sereno, 2012, fig. 28) and Fruitadens (Butler et al., 2012), because the respective phalanx is not preserved. The process is absent in Pisanosaurus (PVL 2577, personal observation; Bonaparte, 1976), indicating that this taxon, wich was argued to be a heterodontosaurid by Casamiquela (1967) and Bonaparte (1976), lies outside of this clade or might represent one of its most basal members.

\section{Considerations on the phylogenetic analysis}

The vertebrate-bearing layer of the Queso Rallado locality consists of a hard, strongly silicified limestone, which makes it impossible to excavate specimens in situ. Vertebrate material from Queso Rallado is therefore collected by separating large blocks of matrix in the quarry and subsequently splitting these blocks in camp. Both the holotype of Manidens condorensis (MPEF-PV 3211) and the specimen MPEF-PV 3826 were found in smaller matrix slabs resulting from this process, but no information about a potential original association of these remains is available, as only preparation in the lab revealed the identity of the remains. Based on morphologic features, MPEFPV 3826 surely represents a small heterodontosaurid, the specimens MPEF-PV 3826 and 3211 are of matching size, and it is conspicuous that the former specimen only contains elements that are missing in the type of $M$. condorensis, indicating that both might represent a single individual. On the other hand, the specimen MPEF-PV 3826 might also represent another individual of Manidens condorensis. However, given the lack of overlap in the specimens and the missing information about a possible association of these remains, none of the possibilities can be proven at the moment. Therefore, a referral of MPEF-PV 3826 to Manidens condorensis may be probable, but is not conclusive. Thus, in the phylogenetic analysis we have alternatively included Manidens condorensis and MPEF-PV 3826 as independent OTUs and as a single OUT (combining the character scorings).

The taxonomic affinity of the specimen NHMUK A100 with Lycorhinus angustidens Haughton, 1924 (= Lanasaurus scalpridens Gow, 1975) is still debated (Butler et al., 2008; Sereno, 2012). Butler et al. (2008) included NHMUK A100 as a separate OTU in their phylogenetic analysis, with some of the characters scored for NHMUK A100 being based on the identifications of Thulborn (1970), who misinterpreted some of the skull bones (e.g., frontal, parietal). The reinterpretation of these elements by Sereno (2012) was followed here and NHMUK A100 was therefore rescored for these features. The referral of NHMUK A100 to Lycorhinus Haughton, 1924, as Thulborn (1970) and Sereno (2012) suggested, was tested by considering the former as a separate OTU from the latter taxon. Lycorhinus angustidens was coded based on the holotype SAM-PK-K3606 
and the referred specimens BP/1/4244, and BP/1/5253. The expanded dataset presented here provides a broader empirical basis to test these issues.

Phylogenetic results. - The data matrix was analyzed using equally weighted parsimony in TNT, version 1.1 (Goloboff et al., 2008a, 2008b). Although the phylogenetic position of Stenopelix Von Meyer, 1857, Yandusaurus He, 1979 and Talenkauen Novas, Cambiaso and Ambrosio, 2004, varies among the most parsimonious trees (MPTs), they were not excluded from the strict consensus tree, because the resolution of the nodes involved was not relevant for our goals (Fig. 10.1; see Supplemental Data 11). The number of MPTs in both analyses does not vary, as both yielded 120 MPTs of 682 steps using Manidens and MPEF-PV 3826 as independent OTUs, and 683 steps considering Manidens and MPEF-PV 3826 as the same taxon. The global topology of the strict consensus tree does not significantly differ from that of Butler et al. (2008) and successive analyses. All species previously referred to Heterodontosauridae are clustered in a monophyletic group (Fig. 10), and Heterodontosaurinae is recovered with the same taxonomic content as found by Sereno (2012). The topology within Heterodontosauridae in the strict consensus tree supports a clade of South African heterodontosaurids (Heterodontosaurus, Abrictosaurus, Lycorhinus, and NHMUK A100), as in Pol et al. (2011), but differing from the hypothesis of Sereno (2012), who retrieved Lycorhinus as a more basal taxon. Lycorhinus and NHMUK A100 were found to be sister taxa, based on a character reversal (absence of considerable size variation in crowns along the cheek toothrow [character 236]), providing support for the identification proposed by Thulborn (1970) and Sereno (2012). This clade was found to be more closely related to Abrictosaurus than to Heterodontosaurus. The sister group relationship of Pegomastax Sereno, 2012 and Manidens retrieved by Sereno (2012) was corroborated in our analysis.
The inclusion of MPEF-PV 3826 within Heterodontosauridae is supported by the presence of seven of 17 synapomorphies of the group (Medial distal tarsal articulates distally with metatarsals I, II and III [character 212]; Metatarsals proximally coossified (character 252) and fused with the medial distal tarsal forming a tarsometatarsus (character 253); Subarctometatarsalian condition [character 255]; Extensor pits present at the distal end of proximal phalanges of pedal digits [character 257]; proximodistally oriented "Hypotarsal-like" process on the plantar side of the medial distal tarsal above metatarsal II [character 258]; and an extensor process located dorsally at the proximal end on the first phalanx of digit III [character 259]). When analyzed as a separate OTU, MPEF-PV 3826 is recovered as sister taxon to the small and basal Chinese taxon Tianyulong, based on the presence of two synapomorphies (similar metatarsal IV / metatarsal III length ratio [character 3], Flexor tubercle in ungual phalanges of pes [character 254]). The referral of MPEF-PV 3826 to Manidens condorensis (including combined character scorings) does not change the position of Manidens within Heterodontosauridae (Fig. 10.3).

\section{Discussion}

Histology.-While the presence of some external osteological features (e.g., complete fusion of the neurocentral sutures of all caudal vertebrae, coossification of the tarsometatarsi [Brochu, 1996; Horner et al., 2000; Cerda and Chinsamy, 2012; Sereno, 2012]) might suggest that MPEF-PV 3826 was a fully-grown individual, histological data supports a subadult ontogenetic stage for this specimen. The subadult condition for the individual is based on the absence of an external fundamental system (EFS or outer circumferential layer) in the outermost cortex. The presence of an EFS indicates that the individual has reached somatic maturity (Chinsamy-Turan, 2005). Regarding sexual maturity, this parameter was historically inferred from a marked transition of the primary cortical bone from fibrolamellar to
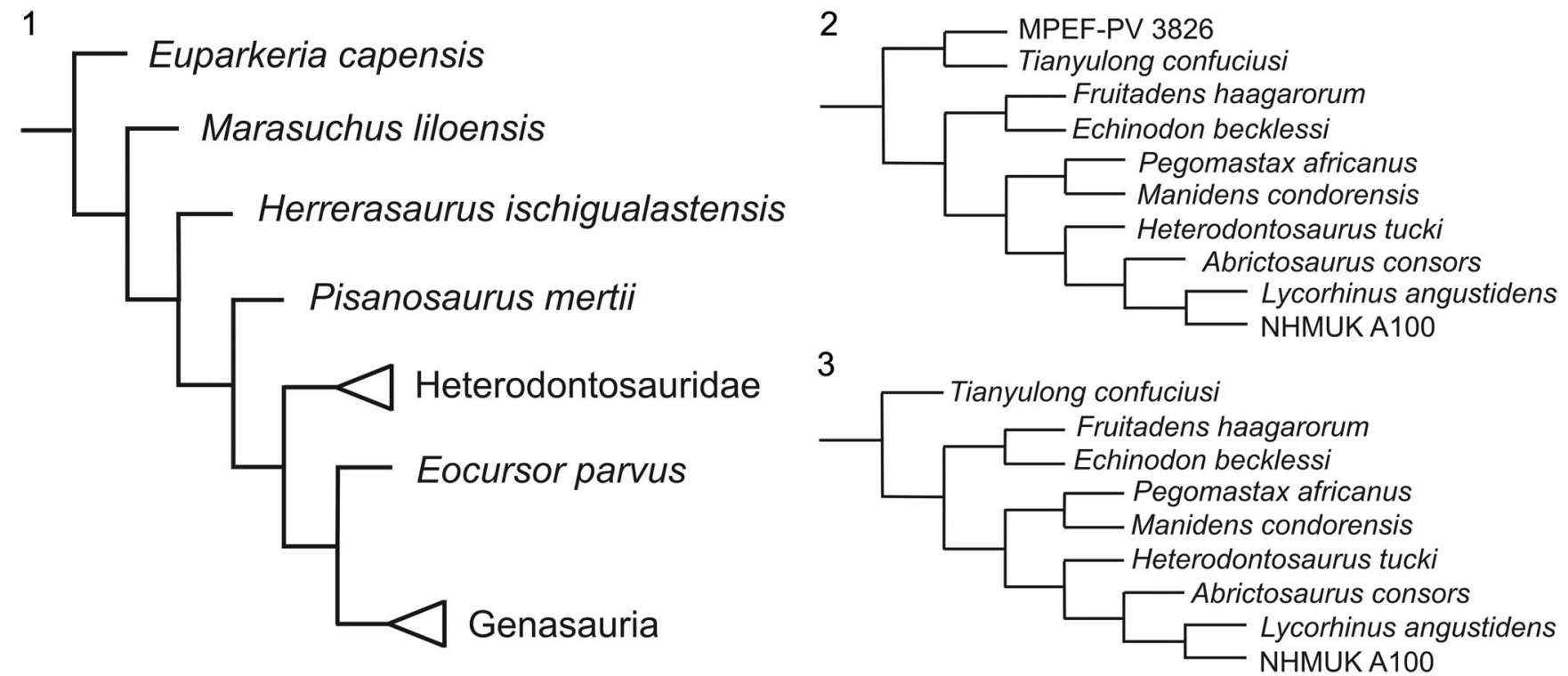

Figure 10. Phylogenetic analysis results: (1) summarized overall topology showing the placement of the taxa of interest, (2) topology of Heterodontosauridae considering MPEF-PV 3826 and Manidens condorensis as independent taxa, (3) topology of Heterodontosauridae considering MPEF-PV 3826 and Manidens condorensis as the same taxon. 
parallel fibred bone and/or a notable decease in the width of the zones in dinosaurs and other ornithodirans. This change results from a slow-down of bone apposition rates in response to energy being redirected from growth to reproduction (Chinsamy-Turan, 2005). Although a slight change in fiber arrangement is observed in the sectioned metatarsal, we consider that this change is not marked enough to indicate a global slow-down in periosteal bone formation and, thus, the reach of sexual maturity. The relative age of the individual could not be assessed because the sampled material lacks growth marks (annuli or lines of arrested growth). This might be related to different causes. If the growth of the element was cyclical, growth marks could be absent because of (1) destruction of early formed growth lines through bone resorption from the medullary cavity, or (2) the individual died before it reached its first annual cycle. On the other hand, if the specimen had continuous growth, LAGs and/or annuli might never have been formed, even in individuals older than 1 year. As noted above in the comparisons with Gasparinisaura, the dominance of fibrolamellar tissue in the middle-outer cortex, could be seen as evidence for a high growth rate (Francillon-Vieillot et al., 1990; Reid, 1996; Chinsamy-Turan, 2005). The presence of external osteological features of maturity that would be expected in adult individuals in a histologically subadult specimen suggests that the former might not be conclusive evidence for ontogenetic interpretations in heterodontosaurids, and the size reached by the taxon represented by MPEF-PV 3826 might be larger than currently documented, as recently found in Heterodontosaurus tucki (Porro et al., 2011). As in MPEF-PV 3826, the Heterodontosaurus specimen SAM-PK-K 1332 also showed the osteological features of individual maturity mentioned (Santa Luca, 1980; Sereno, 2012), but the find and description of NM QR 1788 (Porro et al., 2011) reveal that adult sizes of Heterodontosaurus tucki could reach at least twice of that expected previously.

Cladistic analysis.-Although a possible referral of MPEF-PV 3826 to Manidens cannot be evaluated, due to the lack of overlapping material, both the discrete and continuous characters relate this specimen to the family Heterodontosauridae, with some derived features being shared with the small basal heterodontosaurid Tianyulong. The small size and shared features with Tianyulong (including the inferred grasping function of the pes) may reflect similarities of both taxa in terms of their ecological niche or habits. A referral of MPEF-PV 3826 to $M$. condorensis would increase the anatomical knowledge of this species, but does not affect the phylogenetic position of this taxon. Thus, MPEF-PV 3826 is a small form of Heterodontosauridae that might be identified as Manidens condorensis. The placement of Lycorhinus angustidens and NHMUK A100 as sister taxa support the hypothesis that all specimens (the holotype SAM-PK-K3606, the referred specimens BP/1/4244 and $\mathrm{BP} / 1 / 5253$, and the controversial NHMUK A100) can be referred to the same species, as argued by Thulborn (1970) and Sereno (2012). Concerning the new characters added here, most of these features are present only in Heterodontosauridae: six of the discrete characters were retrieved as synapomorphies for this family (see above), and character 254 (flexor tubercle in ungual phalanges) links MPEF-PV 3826 with Tianyulong. In the new character 256 (lateromedial width in relation to anteroplantar height of distal condyles of metatarsals II and IV) character state "0" (condyles wider lateromedially than anteroplantarly) was found to represent the plesiomorphic condition in dinosaurs, as it was observed in Marasuchus, basal saurischians, basal sauropodomorphs, Pisanosaurus, and heterodontosaurids. The derived condition is present in pachycephalosaurids, basal ornithopods and ankylopolexians. The presence of lateromedially wider distal condyles of metatarsals II and IV is therefore a plesiomorphic feature in heterodontosaurids (present in MPEF-PV 3826) that supports their basal phylogenetic position within Ornithischia. The plesiomorphic condition is present in some derived lineages (e.g., psittacosaurids, ceratopsids, thyreophorans). As with other morphological features of the hindlimb (i.e., robust bones forming a columnar limb, short inner metatarsals that are subequal in length, short digits with discoidal phalanges, etc.), the reversal to the plesiomorphic condition in heavy-bodied lineages of ornithischians might be a response to biomechanic constraints.

Cursorial capabilities. - In comparison with other phylogentically close taxa the relative length of the metatarsus in relation to the mediolateral width of the proximal articular surface shows that the material describe here belongs to a taxon with a gracile pes (more similar to Heterodontosaurus and Gasparinisaura than to Dryosaurus and Thescelosaurus). The closely appressed configuration of the fused tarsometatarsi present in MPEF-PV 3826 probably represents an adaptation to resist the bending stress experienced during the step more efficiently (Holtz, 1995), and, together with the slender and proximodistally elongated morphology, suggest cursorial locomotion with running capabilities in this specimen. Thus, the presence of well-co-ossified tarsometatarsi might be a response to mechanic stress during cursorial movement independently of ontogeny, and although the specimen may represent a histologically advanced growth stage, fusion of the metatarsals and tarsals is not conclusive for inferring somatic maturity of individuals. The flat surface on the plantar region of the unguals (between the flexor tubercle and the proximal articular surface) probably contacted the ground when walking, standing, or running, with the pointed tip of the ungual not participating in the step cycle. The pointed claw was probably used only for a grasping function (as in extant birds).

Grasping capabilities.-The plantarly curved and lateromedially slender claw with an anterior displacement of the flexor tubercle in the pedal ungual phalanges of MPEF-PV 3826 is a combination of features that is absent in other ornithischian dinosaurs, except for Tianyulong. This feature is not present in Heterodontosaurus, which has claw-like, plantarly flat unguals in the pes, which are lateromedially wide and distally elongated, with poorly developed flexor tubercles (SAM-PK-K1332), a common condition in basal ornithischians. Although digit I of MPEF-PV 3826 was certainly too short to reach the ground during normal locomotion, the presence of a deep distal plantar supracondylar fossa in metatarsal I (a feature only described in this specimen among Heterodontosauridae), an extensor pit that is located distally on phalanx I.1, and an anteroplantarly protuberant articular trochlea (allowing a wider range of motion of 
the phalanx) indicate that this digit might have had a grasping function. Furthermore, the lateromedial width of the distal trochlea of metatarsal I, which is similar to that of all other metatarsals (rather than reduced as in other ornithischians), together with the anteroplantarly wide range of motion and the lateral tubercles for ligament attachment (instead of grooves) on both sides of the distal trochlea are features not described in any other heterodontosaurid that also suggest a grasping role of digit I. In summary, the presence of a protuberant, "hypotarsallike" process in the tarsus for attachment of flexor ligaments of the pes, the deep anterior extensor pits for tendon attachments (as found in a wide range of archosauromorph taxa by Hutchinson [2002]) on the distal ends of metatarsals II and III and the first phalanges of all digits (features shared with other heterodontosaurids), the proximally directed and slightly prominent dorsal portion of the proximal articular facet in slender and distally placed phalanges for the attachment of extensor ligaments, elongate penultimate pedal phalanges, the presence of curved and slender claws with strongly developed, distally offset flexor tubercles in ungual phalanges (shared with Tianyulong), and the morphology of the distal trochlea of metatarsal I are all features that strongly suggest a grasping function for the pes in MPEF-PV 3826.

Ecological inferences.-The inclusion of MPEF-PV 3826 and the new characters resulting from this study in the phylogenetic analysis results in the identification of some features (i.e., hypotarsal-like process, subarctometatarsalian condition, claw-like unguals with a prominent flexor tubercle, coossified tarsometatarsi) as specializations of heterodontosaurids (or a subclade thereof) among ornithischians. Although there are many differences to birds (metatarsal I reaches the tarsus and fuses with the tarsals and does not reach the level of the distal end of the other metatarsals in Heterodontosauridae, excluding perching capabilities) some of the features mentioned are convergently present in extant birds (Santa Luca, 1980). The penultimate phalanges on digits II-IV of the pes in MPEF-PV 3826 are longer proximodistally than all other, more proximally placed phalanges of the same digit, a feature not described in any other ornithischian, but shared with several species of perching and climbing arboreal birds, non-avian theropods, pterosaurs and lizards (Fisher, 1946; Zhou and Hou, 1998; Clark et al., 1998; Hopson 2001; Zhou and Farlow, 2001; Kambic, 2008). To characterize digit morphology of MPEF-PV 3826 (and its possible relation to an ecological niche), a comparative analysis of the length of phalanges of digit III was performed. The specimen MPEF-PV 3826 was compared with extant birds of arboreal, terrestrial and undetermined habits (animals displaying both arboreal and terrestrial habits), following the work of Hopson (2001). We furthermore included basal birds (Rahonavis Forster, Sampson, Chiappe and Krause, 1998, Sinornis Sereno and Rao, 1992, and some species of the families Archaeopterygidae and Confuciusornithidae), nonavian theropods for which arboreal habits have been suggested (Epidendrosaurus Zhang, Zhao, $\mathrm{Xu}$ and Wang, 2002 [=Scansoriopteryx Czerkas and Yuan, 2002], Microraptor Xu, Zhou and Wang, 2000b), terrestrial theropods, and several ornithischians, using bibliographic data (see Supplementary Data 12). The data was plotted on a ternary diagram subjected to a Principal Component Analysis. The results reveal that the lengths of the phalanges of digit III of MPEF-PV 3826 lie outside of the proportions seen in other ornithischians. Specimen MPEF-PV 3826 shares the morphospace in the ternary diagram and PCA graphics with extant birds that display arboreal and undetermined habits (both arboreal and terrestrial; Hopson, 2001). Among extinct taxa, MPEF_PV 3826 shares the morphospace with confuciusornithids, and is close to Microraptor and archaeopterygids, which have been considered as species with arboreal habits by some authors (Feduccia, 1993; Hopson, 2001). Thus the placement of MPEF-PV 3826 in the morphospace is suggestive (albeit not conclusive) for an interpretation of arboreal habits in this specimen (Fig. 11.1-11.4; PCA results in Supplemental Data 13). Regarding the anatomy of ungual phalanges, the combination of well-developed flexor tubercles and the claw curvature is not commonly present among ornithischians (see above). Thus, claw morphology may also be indicative of the habits of this specimen, as these features vary among extant birds with different habits (Feduccia, 1993; Pike and Maitland, 2004; Burnham et al., 2011). Following the functional inferences of bony claws derived from their shape by Ostrom (1974), the form of the main body with a rounded and distally offset flexor tubercle in the preserved unguals of Tianyulong (Zheng et al., 2009, supplementary material; Sereno, 2012, fig. 28-29) and MPEF-PV 3826 resembles the condition found in predatory and perching birds. On the other hand, the unguals of Tianyulong and MPEF-PV 3826 share a low curvature with ground birds and ground predators, but with a slightly more robust bony claw, more similar to Archaeopteryx than to both volant and non-volant predatory birds (Ostrom, 1974, fig. 6). Based on quantitative analyses of bony claw curvature, several authors interpreted ecological aspects of Mesozoic dinosaurs, although the shape of the horny sheath of the claw might be more informative to test hypotheses of lifestyle (Burnham et al., 2011). Following Birn-Jeffery et al. (2012), three measurements were taken and several ornithischians were included in their dataset (measure references in Fig. 12.1 and 12.2; included ornithischians and modified data from Birn-Jeffery et al. [2012], are presented in Supplementary Data 14). The resulting box plots based on outer and inner curvatures (inner curvature $=52^{\circ}$; outer curvature $=72^{\circ}$; $\mathrm{CX} / \mathrm{CD}=0.14$ ), find all ornithischians, including Heterodontosaurus, Tianyulong, and MPEF-PV 3826, in the ecomorphological space of ground-dwelling animals (with the latter being close to the outer curvature of predatory forms; Fig. 12.3 and 12.4), such as Compsognathus, Sinornithomimus, and Caudipteryx (Birn-Jeffery et al., 2012). A ground-dwelling lifestyle is also indicated for Tianyulong by the relation of claw thickness to inner and outer curvature (Fig. 12.5 and 12.6), whereas MPEF-PV 3826 shares an inner-curvature/ relative-thickness relation with ground-dwelling forms and an outer-curvature/relative-thickness relation (which is similar to volant and non-volant predatory birds and Mesozoic theropods) with predatory taxa, such to Compsognathus (instead of taxa with a perching/climbing/arboreal behavior; Fig. 12.5 and 12.6). For all other ornithischians and Heterodontosaurus, a ground-dwelling lifestyle is inferred, based on the outer-inner curvature/relative-thickness relations. The morphological features together with the quantitative analyses in comparison 


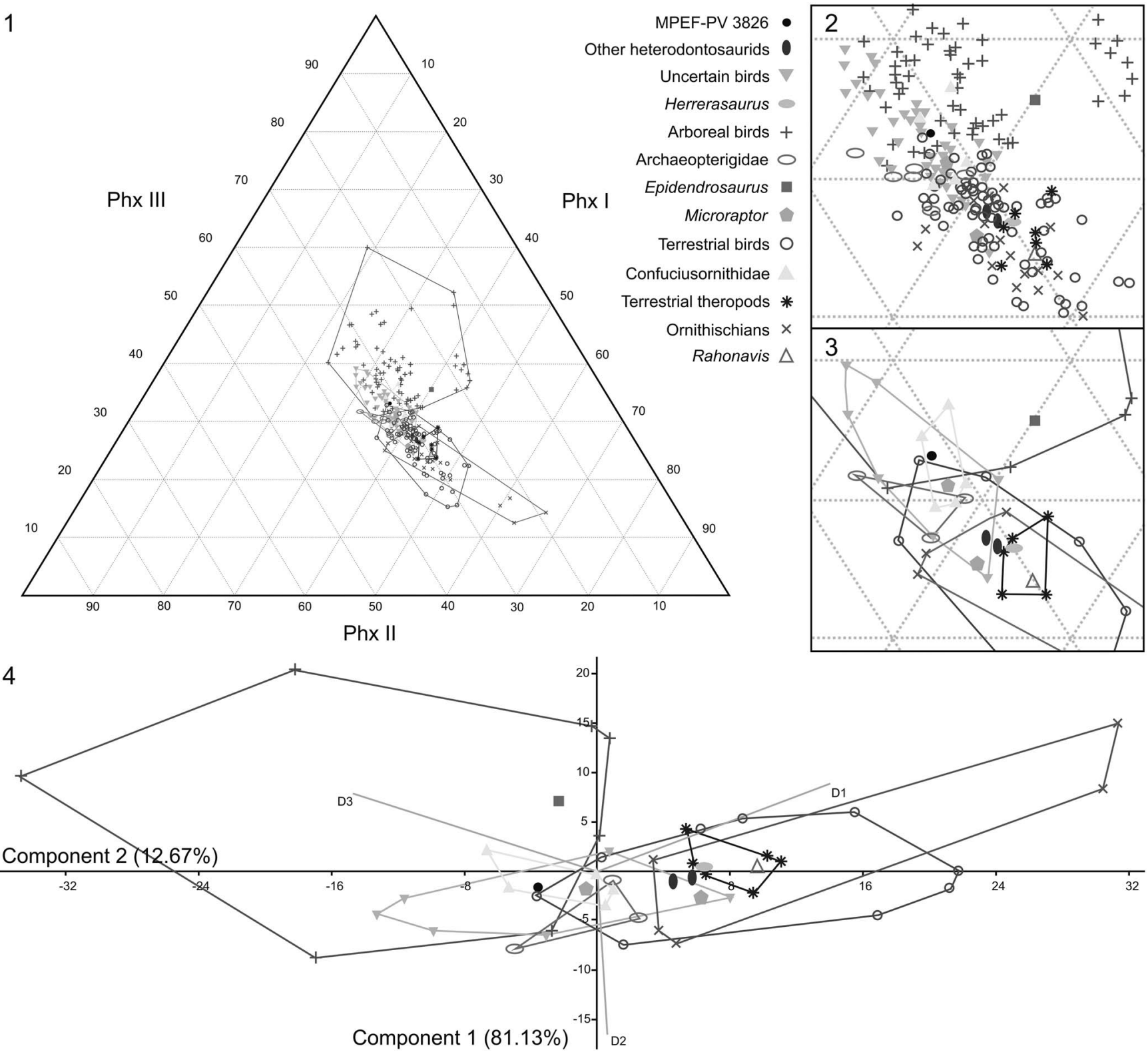

Figure 11. Ternary diagram of ecomorphological spaces of several theropods and ornithischians, using measurements of proportions of non-ungual phalanges of digit III: (1) complete diagram; (2) detail of "uncertain" zone, that includes confuciusornithids, archaeopterygids, arboreal, terrestrial birds and birds of uncertain habits (Following Hopson, 2001), MPEF-PV 3826, several ornithischians, non-avian theropods and other taxa; (3) clean diagram showing convex hulls in the "uncertain zone", summarizing the most important points; (4) principal component analysis using the proportions of non ungual phalanges of digit III, convex hulls of diagram result, note the clustering of MPEF-PV 3826 with extant birds of uncertain habits, actual arboreal birds and confuciusornithids. Symbol references in figure, D1-D2-D3 axes represent the contribution of each original variable to the ternary diagram; D1, first phalanx of digit III axis; D2, second phalanx of digit III axis; D3, third phalanx of digit III axis.

with extant birds and Mesozoic theropods indicate cursorial habits, with probably some arboreal capabilities (based on the analysis of non-ungual phalanges of digit III). The latter might also be supported by the probable grasping abilities of the pes inferred from the morphological comparisons presented above.

\section{Conclusions}

The specimen MPEF-PV 3826 from the late Toarcian Queso Rallado Locality (Cañadón Asfalto Formation) includes two complete metatarsi associated with scattered phalanges and caudal vertebrae. The detailed description, comparison, and morphometric analysis show overall similarities of MPEF-PV 3826 with representatives of the family Heterodontosauridae. Although the referral of MPEF-PV 3826 to Manidens condorensis (found in the same locality and horizon) is likely, there is no osteological evidence to identify this specimen as this taxon, as no overlapping elements are preserved. The phylogenetic results relate MPEF-PV 3826 to Heterodontosauridae, and if these remains are scored as part of Manidens condorensis the phylogenetic position of this taxon does not change in the resulting trees (as the sister taxon of Pegomastax, corroborating the hypothesis of Sereno, 2012). 

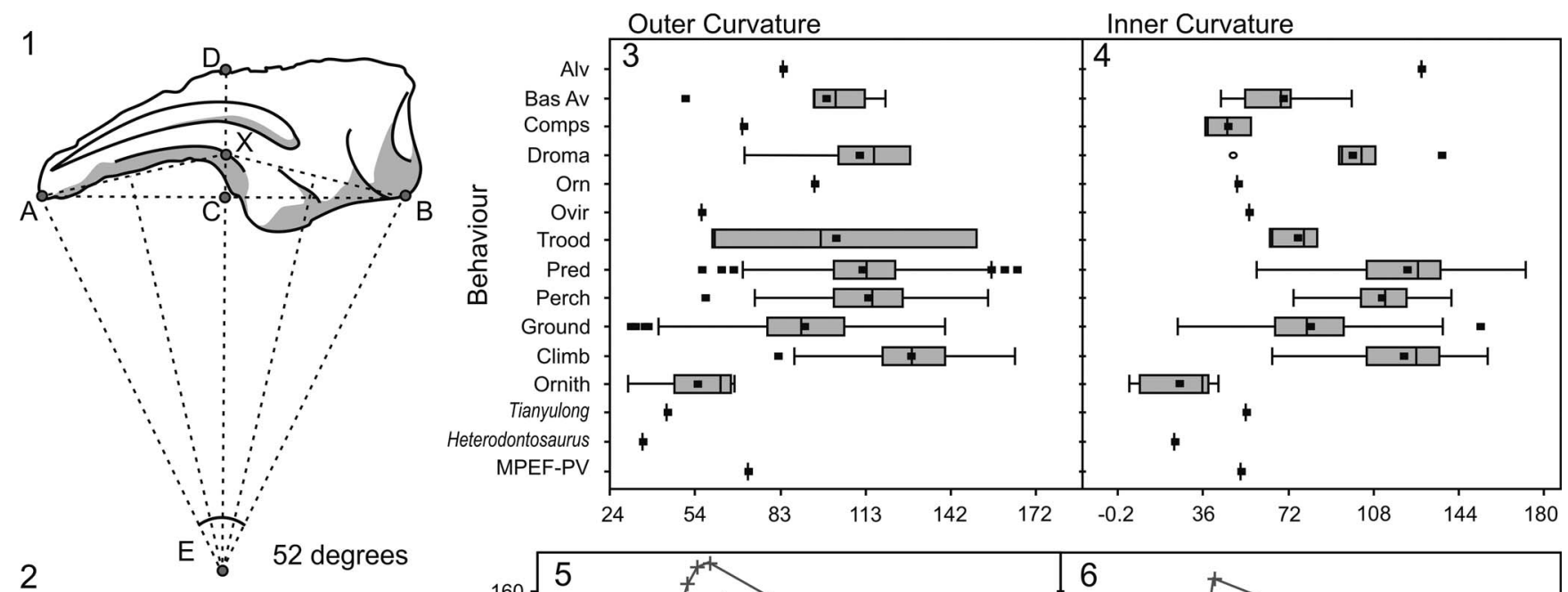

2
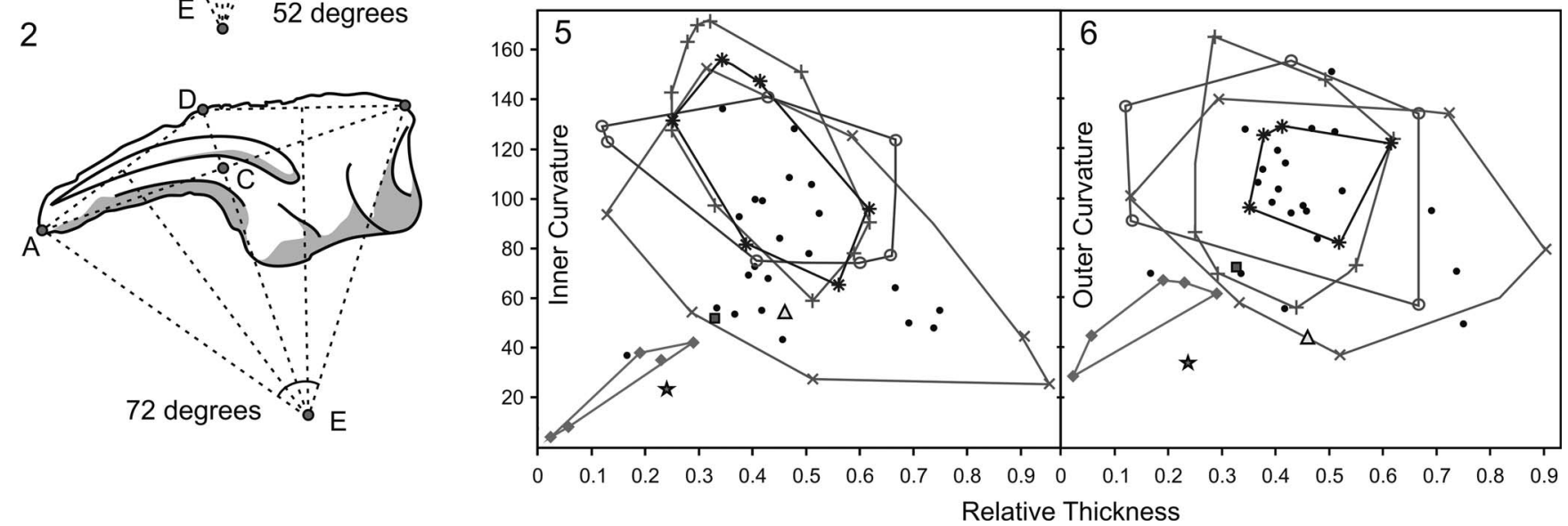

Figure 12. Claw curvature comparison including several actual birds and lizards, with Mesozoic theropods (following Birn-Jeffery et al., 2012), and several ornithischian taxa (Scelidosaurus, Othnielosaurus, Hadrosaurine indet., Anabisetia, Gasparinisaura, Tianyulong): (1) inner claw curvature and relative thickness (CX/CD) measured on most complete ungual phalanx of MPEF-PV 3826 (modified from Birn-Jeffery et al., 2012); (2) Outer claw curvature of the same phalanx (modified from Birn-Jeffery et al., 2012); (3) Box plots for outer claw curvature distinguished by behavioral category, including all data presented by Birn-Jeffery et al. (2012), and adding several ornithischians; (4) as in 12.3 but resampling the inner curvature; (5) inner claw curvature plotted against relative thickness of the claw; (6) outer claw curvature plotted against relative thickness of the claw. For $(\mathbf{3})$ and $(\mathbf{4})$, both box plots were performed following specifications by Birn-Jeffery et al. (2012), with the addition of the average information as a dot within the shaded boxes and considering also the information of Mesozoic theropods. In (5) and (6), convex hulls summarizing the obtained results, configuration of convex hulls and Mesozoic theropods were obtained similar to Birn-Jeffery et al. (2012). References at family level, for species references see Birn-Jeffery et al. (2012): Alv, Alvaresaurid; Bas Av, basal Avialae; Climb, Cimbing extant birds and lizards; Comps, Compsognathidae; Drom, Dromaesauridae; Ground, ground-dwelling extant birds and lizards; Orn, Ornithomimosauria; Orn, Ornithischia; Ovir, Oviraptorosauria; Perch, perching extant birds and lizards; Pred, predatory extant birds and lizards; Tianyulong specimen IVPP V17090; Trood, Troodontidae. *, climbing species; +, predatory species; $\circ$, perching species; x, ground-dwelling species; $\diamond$, ornithischians; ๑, Mesozoic theropods; $\Delta$, Tianyulong IVPP V17090; * Heterodontosaurus SAM-PK-K 1332; $\square$, MPEF-PV 3826.

The histological thin sections and comparisons with the metatarsi of Heterodontosaurus indicate that the remains described here probably pertain to a sub-adult individual rather than a full-grown specimen (as for Heterodontosaurus specimens SAM-PK-K1332 and NM QR 1788 mentioned by Porro et al., 2011).

The morphological comparison of the pes with that of other ornithischian taxa reveals the presence of new apomorphic features for Heterodontosauridae that distinguish this family even more from other ornithischians.

The reconstruction of the pes shows long and tightly appressed metatarsals with digits that are elongated in comparison with other ornithischian taxa (including other heterodontosaurids). A comparative analysis of the length ratio of non-ungual phalanges of digit III denotes similarities with both arboreal and ground-dwelling bird taxa. In contrast, comparative analysis of the pedal ungual phalanx reveals similarities of this specimen with predatory forms. These results might indicate cursorial, grounddwelling behavior, but with a grasping pes and even possibly facultative arboreal capabilities in MPEF-PV 3826. Nonetheless, more information is needed to thoroughly test these hypotheses, including articulated remains that will allow testing the putative referral of this material to Manidens condorensis, as well as remains of the forelimb that is completely unknown for this taxon up to now.

\section{Acknowledgments}

Fieldwork and research were funded by ANPCyT PICT 1756, 0808 (to D.P.), DFG RA1012/9-1 (to O.W.M.R.), National Science Foundation grants DEB 0946430 and DEB 1068089 (to Dr. Guillermo Rougier), and international collaboration grant CONICET-Chinese Academy of Sciences to DP. We thank R. Coria for the measurements of the pes of Anabisetia saldiviai, 
I. Diaz Martinez for the help with character setup and the ornithischian photographic material he shared freely, Lic. D. Perez for the help in searching bibliography, L. Canessa for the mechanical preparation of the specimen MPEF-PV 3826, and M. Caffa for the thin section of metatarsal IV. We furthermore thank J. M. Leardi, C. Marsicano, and L. Gaetano for information on South African heterodontosaurids and basal ornithischians. S. Kaal is thanked for access to comparative specimens of Heterodontosaurus at the Iziko-South African Museum to DP. X.-T. Zheng is thanked for access to comparative specimens of Tianyulong at the Shandong Tianyu Museum of Nature to D.P. X. Zhang is also thanked for her help, and $\mathrm{X}$. $\mathrm{Xu}$ is thanked for providing access to other relevant comparative material. Fieldwork was made possible by the authorities of the Secretaría de Cultura de la Provincia del Chubut.

\section{Accessibility of supplementary data}

Data available from the Dryad Digital Repository: http:// datadryad.org/review?doi=doi:10.5061/dryad.gn960

\section{References}

Apaldetti, C., Pol, D., and Yates, A., 2013, The postcranial anatomy of Coloradisaurus brevis (Dinosauria: Sauropodomorpha) from the Late Triassic of Argentina and its phylogenetic implications: Palaeontology, v. 56 , p. $277-301$.

Baumel, J.J., and Witmer, L.M., 1993, Osteologia, in Baumel, J.J., King, A.S., Brazile, J.E., Evans, H.E., and Vanden Berge, J.C., eds., Handbook of Avian Anatomy: Nomina Anatomica Avium, 2d ed.: Cambridge, UK, Nuttall Ornithological Society, p. 45-132.

Becerra, M.G., Pol, D., Marsicano, C.A., and Rauhut, O.W.M., 2014, The dentition of Manidens condorensis (Ornithischia; Heterodontosauridae) from the Jurassic Cañadón Asfalto Formation of Patagonia: morphology, heterodonty and the use of statistical methods for identifying isolated teeth: Historical Biology, v. 26, p. 480-492.

Birn-Jeffery, A.V., Miller, C.E., Naish, D., Rayfield, E.J., and Hone, D.W.E., 2012, Pedal claw curvature in birds, lizards and Mesozoic dinosaurs complicated categories and compensating for mass-specific and phylogenetic control: PLoS One, v. 7, p. e50555.

Bonaparte, J.F., 1976, Pisanosaurus mertii Casamiquela and the origin of the Ornithischia: Journal of Paleontology, v. 50, p. 808-820.

Bonaparte, J.F., 1978, Coloradia brevis n. g. et n. sp. (Saurischia-Prosauropoda), dinosaurio Plateosauridae de la Formación Los Colorados, Triásico superior de La Rioja, Argentina: Ameghiniana, v. 15, p. 327-332.

Boulenger, G.A., 1881, Iguanodon bernissartensis, in van Beneden, P.-J., ed., Sur l'arc pelvien chez les dinosauriens de Bernissart: Bulletins de 1’Académie Royale des Sciences, des Lettres et des Beaux-Arts de Belgique, Classe des Sciences, v. 1, p. 600-606.

Brochu, C.A., 1996, Closure of neurocentral sutures during crocodilian ontogeny: implications for maturity assessment in fossil archosaurs: Journa of Vertebrate Paleontology, v. 16, p. 49-62.

Burnham, D.A., Feduccia, A., Martin, L.D., and Falk, A.R., 2011, Tree climbing-a fundamental avian adaptation: Journal of Systematic Palaeontology, v. 9, p. 103-107.

Butler, R.J., 2005, The 'fabrosaurid' ornithischian dinosaurs of the Upper Elliot Formation (Lower Jurassic) of South Africa and Lesotho: Zoological Journal of the Linnean Society, v. 145, p. 175-218.

Butler, R.J., Smith, R.M.H., and Norman, D.B., 2007, A primitive ornithischian dinosaur from the Late Triassic of South Africa, and the early evolution and diversification of Ornithischia: Proceedings of the Royal Society B, v. 274, p. 2041-2046.

Butler, R.J., Upchurch, P., and Norman, D.B., 2008, The phylogeny of the ornithischian dinosaurs: Journal of Systematic Palaeontology, v. 6, p. 1-40.

Butler, R.J., Porro, L.B., Galton, P.M., Chiappe, L.M., Henderson, D.M., and Erickson, G.M., 2010, Lower limits of ornithischian dinosaur body size inferred from a new Upper Jurassic heterodontosaurid from North America: Proceedings of the Royal Society B, v. 277, p. 375-381.

Butler, R.J., Liyong, J., Jun, C., and Godefroit, P., 2011, The postcranial osteology and phylogenetic position of the small ornithischian dinosaur Changchunsaurus parvus from the Quantou Formation (Cretaceous:
Aptian-Cenomanian) of Jilin province, north-eastern China: Palaeontology, v. 54 , p. $667-683$.

Butler, R.J., Porro, L.B., Galton, P.M., and Chiappe, L.M., 2012, Anatomy and cranial functional morphology of the small-bodied dinosaur Fruitadens haagarorum from the Upper Jurassic of the USA: PLoS One, v. 7, p. e31556.

Cabaleri, N., Volkheimer, W., Armella, C., Gallego, O., Silva Nieto, D., Páez, M., Cagnoni, M., Ramos, A., Panarello, H., and Koukharsky, M., 2010, Estratigrafía, análisis de facies y paleoambientes de la Formación Cañadón Asfalto en el depocentro jurásico Cerro Cóndor, provincia del Chubut: Revista de la Asociación Geológica Argentina, v. 66, p. 349-367.

Casamiquela, R.M., 1967, Un nuevo dinosaurio ornitisquio Triásico (Pisanosaurus mertii: Ornithopoda) de la Formación Ischigualasto, Argentina: Ameghiniana, v. 4, p. 47-64.

Carpenter, K., 2004, Redescription of Ankylosaurus magniventris Brown 1908 (Ankylosauridae) from the Upper Cretaceous of the Western Interior of North America: Canadian Journal of Earth and Science, v. 41, p. 961-986.

Cerda, I.A., and Chinsamy, A., 2012, Biological implications of the bone microstructure of the Late Cretaceous ornithopod dinosaur Gasparinisaura cincosaltensis: Journal of Vertebrate Paleontology, v. 32, p. 355-368.

Chinsamy, A., 1995, Ontogenetic changes in the bone histology of the Late Jurassic ornithopod Dryosaurus lettowvorbecki: Journal of Vertebrate Paleontology, v. 15, p 96-104.

Chinsamy, A., and Raath, M.A., 1992, Preparation of fossil bone for histological examination: Paleontologia Africana, v. 29, p. 39-44.

Chinsamy-Turan, A., 2005, The microstructure of dinosaur bone, p. deciphering biology with fine-scale techniques: Johns Hopkins University Press, Baltimore and London, $195 \mathrm{p}$.

Clark, J.M., Hopson, J.A., Hernandez, R., Fastovsky, D.E., and Montellano, M., 1998, Foot posture in a primitive pterosaur: Nature, v. 391, p. 886-889.

Colbert, E.H., 1981, A primitive ornithischian dinosaur from the Kayenta Formation of Arizona: Museum of Northern Arizona Press, Bulletin Series, v. 53 , p. $1-61$.

Coombs, W.P. Jr., 1978, Theoretical aspects of cursorial adaptations in dinosaurs: The Quarterly Review of Biology, v. 53, p. 393-418.

Coria, R.A., and Calvo, J.O., 2002, A new iguanodontian ornithopod from Neuquén Basin, Patagonia, Argentina: Journal of Vertebrate Paleontology, v. 22 , p. $503-509$.

Coria, R.A., and Salgado, L., 1996, A basal iguanodontian (Ornithischia: Ornithopoda) from the Late Cretaceous of South America: Journal of Vertebrate Paleontology, v. 16, p. 445-457.

Crompton, A.W., and Charig, A.J., 1962, A new ornithischian from the Upper Triassic of South Africa: Nature, v. 196, p. 1074-1077.

Cuneo, R., Ramezani, J., Scasso, R., Pol, D., Escapa, I., Zavattieri, A.M., and Bowring, S.A., 2013, High-precision U-Pb geochronology and a new chronostratigraphy for the Cañadón Asfalto Basin, Chubut, central Patagonia: Implications for terrestrial faunal and floral evolution in Jurassic: Gondwana Research, v. 24, p. 1267-1275.

Czerkas, S.A., and Yuan, C., 2002, An arboreal maniraptoran from northeast China, p. 63-95. In S. J. Czerkas (ed.), The Dinosaur Museum Journal 1, Feathered dinosaurs and the origin of flight: Blanding, UT.

Di Rienzo, J.A., Casanoves, F., Balzarini, M.G., Gonzalez, L., Tablada, M., and Robledo, C.W., 2011, InfoStat versión 2011: Grupo InfoStat, FCA, Universidad Nacional de Córdoba, Argentina.

Dodson, P., Forster, C.A., and Sampson, S.D., 2004, Ceratopsidae, in Weishampel, D.B., Dodson, P., and Osmólska, H., eds., The Dinosauria, 2d ed.: Berkeley, University of California Press, p. 494-514.

Dong, Z., 1978, A new genus of Pachycephalosauria from Laiyang, Shantung: Vertebrata PalAsiatica, v. 16, p. 225-228. [in Chinese]

Dong, Z., 1989, On a small ornithopod (Gongbusaurus wucaiwanensis sp. nov.) from Kelamaili Junggar Basin, Xinjiang, China]: Vertebrata PalAsiatica, v. 27, p. 140-146. [in Chinese]

Dong, Z., and Azuma, Y., 1997, On a primitive neoceratopsian from the Early Cretaceous, in Dong, Z.-M., ed: Sino-Japanese Silk Road Dinosaur Expedition, Beijing, China Ocean Press, p. 68-89.

Escapa, I.H., Sterli, J., Pol, D., and Nicoli, L., 2008, Jurassic tetrapods and flora of Cañadón Asfalto Formation in Cerro Condor area, Chubut Province: Revista de la Asociación Geológica Argentina, v. 63, p. 613-624.

Farris, J.S., 1981, Distance data in phylogenetic analysis, in Funk, V.A., and Brooks, D.R., eds., Advances in Cladistics, vol I: Proceedings of the First Meeting of the Willi Henning Society, New York Botanical Garden, New York. p. 1-23.

Feduccia, A., 1993, Evidence from claw geometry indicating arboreal habits of Archaeopteryx: Science, v. 259, p. 790-793.

Fisher, H.I., 1946, Adaptations and comparative anatomy of the locomotor apparatus of New World vultures: American Midland Naturalist, v. 35, p. 545-727.

Forster, C.A., Sampson, S.D., Chiappe, L.M., and Krause, D.W., 1998, The theropod ancestry of birds: New evidence from the Late Cretaceous of Madagascar: Science, v. 279, p. 1915-1919. 
Fracillon-Vieillont, H., Debuffrénil, V., Castanet, J., Geraudie, J., Meurier, F.J., Sire, J.Y., Zylberberg, L., and De Ricqlés, A., 1990, Microstructure and mineralization of vertebrate skeletal tissues, in Carter, J.G., ed., Skeletal Biomineralization: Patterns, Processes and Evolutionary Trends, volume 1, New York, Van Nostrand Reinhold, p. 471-530.

Galton, P.M., 1974a, Notes on Thescelosaurus, a conservative ornithopod dinosaur from the Upper Cretaceous of North America, with comments on ornithopod classification: Journal of Paleontology, v. 48, p. 1048-1067.

Galton, P.M., 1974b, The ornithischian dinosaur Hypsilophodon from the Wealden of the Isle of Wight: Bulletin of the British Museum (Natural History) Geology, v. 25, p. 1-152.

Galton, P.M., 1978, Fabrosauridae, the basal family of ornithischian dinosaurs (Reptilia: Ornithopoda): Paläontologische Zeitschrift, v. 52, p. 138-159.

Galton, P.M., 1981, Dryosaurus, a hypsilophodontid dinosaur from the Upper Jurassic of North America and Africa: postcranial skeleton: Paläontologische Zeitschrift, v. 55, p. 271-312.

Galton, P.M., 2006, Teeth of ornithischian dinosaurs (mostly Ornithopoda) from the Morrison Formation (Upper Jurassic) of Western United States, in Carpenter, K., ed., Horns and Beaks, Ceratopsian and Ornithopod Dinosaurs, Bloomington, Indiana University Press, p. 17-47.

Galton, P.M., and Jensen, J.A., 1973, Skeleton of a hypsilophodontid dinosaur (Nanosaurus (?) rex) from the Upper Jurassic of Utah: Brigham Young University Geology Studies, v. 20, p. 137-157.

Galton, P.M., and Powell, H.P., 1980, The ornithischian dinosaur Camptosaurus prestwichii from the Upper Jurassic of England: Palaeontology, v. 23, p. 411-443.

Galton, P.M., and Upchurch, P., 2004a, Prosauropoda, in Weishampel, D.B., Dodson, P., and Osmólska, H., eds., The Dinosauria, 2d ed.: Berkeley, University of California Press, p 393-412.

Galton, P.M., and Upchurch, P., 2004b, Stegosauridae, in Weishampel, D.B., Dodson, P., and Osmólska, H., eds., The Dinosauria, 2d ed.: Berkeley, University of California Press, p. 343-362.

Gilmore, C.W., 1909, Osteology of the Jurassic reptile Camptosaurus, with a revision of the species of the genus and a description of two new species: Proceedings of the U.S. National Museum, v. 36, p. 197-332.

Gilmore, C.W., 1913, A new dinosaur from the Lance Formation of Wyoming: Smithsonian Miscellaneous Collection, v. 61, p. 1-5.

Gilmore, C.W., 1914, Osteology of the armored dinosaurs in the United States National Museum, with special reference to the genus Stegosaurus: Bulletin of the U.S. National Museum, v. 89, p. 1-136.

Gilmore, C.W., 1915, Osteology of Thescelosaurus, an orthopodous dinosaur from the Lance Formation of Wyoming: Proceedings of the U.S. National Museum, v. 49, p. 591-616.

Goloboff, P.A., Farris, J.S., and Nixon, K.C., 2008a, TNT, a free program for phylogenetic analysis: Cladistics, v. 24, p. 1-13.

Goloboff, P.A., Farris, J.S., and Nixon, K.C., 2008b, TNT (Tree analysis using new technology) ver. 1.1.: Published by the authors, Tucumán, Argentina.

Gow, C.E., 1975, A new heterodontosaurid from the Red Beds of South Africa showing clear evidence of tooth replacement: Zoological Journal of the Linnean Society, v. 57, p. 335-339.

Hammer, O., Harper, D.A.T., and Ryan, P.D., 2001, PAST: Paleontological Statistics software package for education and data analysis: Palaeontologica Electronica, v. 4, 9 p.

Han, F.L., Barrett, P.M., Butler, R.J., and Xu, X., 2012, Postcranial anatomy of Jeholosaurus shangyuanensis (Dinosauria, Ornithischia) from the Lower Cretaceous Yixian Formation of China: Journal of Vertebrate Paleontology, v. 32 , p. $1370-1395$.

Haughton, H., 1924, The fauna and stratigraphy of the Stormberg Series: Annals of the South African Museum, v. 12, p. 323-497.

Hayashi, S., Carpenter, K., and Suzuki, D., 2009, Different growth patterns between the skeleton and osteoderms of Stegosaurus (Ornithischia: Thyreophora): Journal of Vertebrate Paleontology, v. 29, p. 123-131.

He, X., 1979, A newly discovered ornithopod dinosaur-Yandusaurus from Zigong, China, in Contributions to International Exchange of Geology, Part 2, Stratigraphy and Palaeontology: Beijing, Geological Publishing House, p. 116-123. [in Chinese]

Holtz, T.R. Jr., 1994, The arctometatarsalian pes, an unusual structure of Cretaceous Theropoda (Dinosauria: Saurischia): Journal of Vertebrate Paleontology, v. 14, p. 408-519.

Hooley, R.W., 1925, On the skeleton of Iguanodon atherfieldensis sp. nov., from the Wealden Shales of Atherfield (Isle of Wight): Quarterly Journal of the Geological Society, v. 81, p. 1-61.

Hopson, J.A., 1975, On the generic separation of the ornithischian dinosaurs Lycorhinus and Heterodontosaurus from the Stormberg Series (Upper Triassic) of South Africa: South African Journal of Science, v. 71, p. 302-305.

Hopson, J.A., 2001, Ecomorphology of avian and theropod phalangeal proportions, p. implications for the arboreal versus terrestrial origin of bird flight, in Gauthier, J., and Gall, L.F., eds., New Perspectives on the Origin and Early Evolution of Birds: Special Publication of the Peabody Museum of Natural History, Yale University, p. 211-235.

Horner, J.R., and Makela, R., 1979, Nest of juveniles provides evidence of family structure among dinosaurs: Nature, v. 282, p. 296-298.

Horner, J.R., and Weishampel, D.B., 1988, A comparative embryological study of two ornithischian dinosaurs: Nature, v. 332, p. 256-257.

Horner, J.R., De Ricqlés, A., and Padian, K., 2000, Long bone histology of the hadrosaurid dinosaur Maiasaura peeblesorum: growth dynamics and physiology based on an ontogenetic series of skeletal elements: Journal of Vertebrate Paleontology, v. 20, p. 115-129.

Horner, J.R., Weishampel, D.B., and Forster, C.A., 2004, Hadrosauridae, in Weishampel, D.B., Dodson, P., and Osmólska, H., eds., The Dinosauria, 2d ed.: Berkeley, University of California Press, p. 438-463.

Horner, J.R., De Ricqlés, A., Padian, K., and Scheetz, R.D., 2009, Comparative long bone histology and growth of the 'hypsilophodontid' dinosaurs Orodromeus makelai, Dryosaurus altus, and Tenontosaurus tilletii (Ornithischia: Euornithopoda): Journal of Vertebrate Paleontology, v. 29, p. 734-747.

Hou, L., 1977, A new primitive Pachycephalosauria from Anhui, China: Vertebrata PalAsiatica, v. 15, p. 198-202. [in Chinese]

Hübner, T.R., 2012, Bone histology in Dysalotosaurus lettowvorbecki (Ornithischia: Iguanodontia)-variation, growth, and implications: PLoS One, v. 7, e29958.

Huene, F.V., 1908, Die Dinosaurier der europäischen Triasformation mit Berücksichtigung der aussereuropäischen Vorkommnisse: Geologische und Palaeontologische Abhandlungen, Supplement, v. 1, p. 1-419.

Hutchinson, J.R., 2002, The evolution of hindlimb tendons and muscles on the line to crown-group birds: Comparative Biochemistry and Physiology Part A, v. 133 , p. $1051-1086$

Huxley, T.H., 1869, On Hypsilophodon, a new genus of Dinosauria: Abstracts of the Proceedings of the Geological Society of London, v. 204, p. 3-4.

Irmis, R.B., 2007, Axial skeleton ontogeny in the Parasuchia (Archosauria: Pseudosuchia) and its implications for ontogenetic determination in Archosaurs: Journal of Vertebrate Paleontology, v. 27, p. 350-361.

Irmis, R.B., Parker, W.G., Nesbitt, S.J., and Liu, J., 2007, Ornithischian dinosaurs: the Triassic record: Historical Biology, v. 18, p. 3-22.

Kambic, R.E., 2008, Multivariate analysis of avian and non-avian theropod pedal phalanges, Unpublished Ph.D. dissertation: Bozeman, Montana State University, $90 \mathrm{p}$.

Langer, M.C., 2004, Basal Saurischia, in Weishampel, D.B., Dodson, P., and Osmólska, H., eds., The Dinosauria, 2d ed.: Berkeley, University of California Press, p 25-46.

Longrich, N., 2010, The function of large eyes in Protoceratops: a nocturnal ceratopsian?, in Ryan, M.J., Chinnery-Allgeier, B.J., and Eberth, D.A., eds., New Perspectives on Horned Dinosaurs, The Royal Tyrrell Museum Ceratopsian Symposium, Bloomington and Indianapolis, Indiana University Press, p. 308-327.

Makovicky, P.J., and Norell, M.A., 2004, Troodontidae, in Weishampel, D.B., Dodson, P., and Osmólska, H., eds., The Dinosauria, 2d ed.: Berkeley, University of California Press, p. 184-195.

Mantell, G.A., 1825, Notice on the Iguanodon, a newly discovered fossil reptile, from the sandstone of Tilgate Forest, in Sussex: Philosophical Transactions of the Royal Society of London, v. 115, p. 179-186.

Marsh, O.C., 1878, Principal characters of American Jurassic dinosaurs. Part I: American Journal of Science, v. 16, p. 411-416.

Marsh, O.C., 1879, Notice of new Jurassic reptiles: American Journal of Science, v. 18, p. 501-505.

Marsh, O.C., 1885, Names of extinct reptiles: American Journal of Science, v. 29 , p. 169.

Marsh, O.C., 1894, The typical Ornithopoda of the American Jurassic: American Journal of Science, v. 283, p. 85-90.

Maryanska, T., and Osmólska, H., 1974, Pachycephalosauria, a new suborder of ornithischian dinosaurs: Palaeontologia. Polonica, v. 30, p. 45-102.

Norell, M.A., and Makovicky, P.J., 2004, Dromaeosauridae, in Weishampel, D.B., Dodson, P., and Osmólska, H., eds., The Dinosauria, 2d ed.: Berkeley, University of California Press, p. 196-209.

Norman, D.B., 1980, On the ornithischian dinosaur Iguanodon bernissartensis from Belgium: Mémoire de Institut Royal des Sciences Naturelles de Belgique, v. 178, p. 1-103.

Norman, D.B., 2004, Basal Iguanodontia, in Weishampel, D.B., Dodson, P., and Osmólska, H., eds., The Dinosauria, $2 \mathrm{~d}$ ed.: Berkeley, University of California Press, p. 413-437.

Norman, D.B., Sues, H.-D., Witmer, L.M., and Coria, R.A., 2004, Basal Ornithopoda, in Weishampel, D.B., Dodson, P., and Osmólska, H., eds., The Dinosauria, 2d ed.: Berkeley, University of California Press, p. 393-412.

Novas, F.E., 1993, New information on the systematics and postcranial skeleton of Herrerasaurus ischigualastensis (Theropoda: Herrerasauridae) from the 
Ischigualasto Formation (Upper Triassic) of Argentina: Journal of Vertebrate Paleontology, v. 13, p. 400-423.

Novas, F.E., Cambiaso, A., and Ambrosio, A., 2004, A new basal iguanodontian (Dinosauria, Ornithischia) from the Upper Cretaceous of Patagonia: Ameghiniana, v. 41, p. 75-82.

Perle, A., Maryańska, T., and Osmólska, H., 1982, Goyocephale lattimoeri gen. et sp. n., a new flat-headed pachycephalosaur (Ornithischia, Dinosauria) from the Upper Cretaceous of Mongolia: Acta Palaeontologica Polonica, v. 27, p. $115-127$.

Osborn, H.F., 1923, Two Lower Cretaceous dinosaurs of Mongolia: American Museum Novitates, v. 95, p. 1-10.

Osborn, H.F., 1924, Psittacosaurus and Protiguanodon, $p$. Two Lower Cretaceous iguanodonts from Mongolia: American Museum Novitates, v. 127, p. $1-16$.

Osmólska, H., 1981, Coossified tarsometatarsi in theropod dinosaurs and their bearing on the problem of bird origins: Acta Paleontologica Polonica, v. 42, p. 79-95.

Osmólska, H., Currie, P.J., and Barsbold, R., 2004, Oviraptorosauria, in Weishampel, D.B., Dodson, P., and Osmólska, H., eds., The Dinosauria $2 d$ ed.: Berkeley, University of California Press, p. 165-183.

Ostrom, J.H., 1969, Osteology of Deinonychus antirrhopus, an unusual theropod from the Lower Cretaceous of Montana: Bulletin of the Peabody Museum of Natural History, v. 30, p. 1-165.

Ostrom, J.H., 1970, Stratigraphy and paleontology of the Cloverly Formation (Lower Cretaceous) of the Bighorn Basin area, Wyoming and Montana: Bulletin of the Peabody Museum of Natural History, v. 35, p. 1-234.

Ostrom, J.H., 1974, Archaeopteryx and the origin of flight: The Quarterly Review of Biology, v. 49, p. 27-47.

Owen, R., 1861, Monograph of the Fossil Reptilia of the Liassic formations. Part 1. A monograph of a fossil dinosaur (Scelidosaurus harrisonii Owen) of the Lower Lias: Palaeontographical Society Monographs, v. 1, p. $1-14$.

Padian, K., 2004, Basal Avialae, in Weishampel, D.B., Dodson, P., and Osmólska, H., eds., The Dinosauria, 2d ed.: Berkeley, University of California Press, p. 196-209.

Parks, W.A., 1926, Thescelosaurus warreni, a new species of ornithopodous dinosaur from the Edmonton Formation of Alberta: University of Toronto Studies (Geological Series), v. 21, p. 1-42.

Peng, G.-Z., 1990, A new species of small ornithopod from Zigong, Sichuan: Journal of the Zigong Dinosaur Museum, v. 2, p. 19-27. [in Chinese]

Peng, G.-Z., 1992, Jurassic ornithopod Agilisaurus louderbacki (Ornithopoda: Fabrosauridae) from Zigong, Sichuan, China: Vertebrata PalAsiatica, v. 30 p. 39-51. [in Chinese]

Pike, A.V.L., and Maitland, D.P., 2004, Scaling of bird claws: Journal of Zoology, v. 262, p. 73-81.

Pol, D., Rauhut, O.W.M., and Becerra, M.G., 2011, A Middle Jurassic heterodontosaurid dinosaur from Patagonia and the evolution of heterodontosaurids: Naturwissenschaften, v. 98, p. 369-379.

Porro, L.B., Butler, R.J., Barrett, P.M., Moore-Fay, S., and Abel, R.L., 2011, New heterodontosaurid specimens from the Lower Jurassic of southern Africa and the early ornithischian dinosaur radiation: Earth and Environmental Transactions of the Royal Society of Edinburgh, v. 101, p. 351-366.

Redelstorff, R., Hübner, T.R., Chinsamy, A., and Sander, P.M., 2013, Bone histology of the stegosaur Kentrosaurus aethiopicus (Ornithischia: Thyreophora) from the Upper Jurassic of Tanzania: The Anatomical Record, v. 296, p. 933-952.

Reid, R.E.H., 1996, Bone histology of the Cleveland-Lloyd dinosaurs and of dinosaurs in general, part I: introduction to bone tissues: Brigham Young University Geology Studies, v. 41, p. 25-72.

Reig, O.A., 1963, La presencia de dinosaurios saurisquios en los "Estratos de Ischigualasto" (Mesotrifisico superior) de las provencias de San Juan y La Rioja (Republica Argentina): Ameghiniana, v. 3, p. 3-20.

Romer, A.S., 1972, The Chañares (Argentina) Triassic reptile fauna. XV. Further remains of the thecodonts Lagerpeton and Lagosuchus: Breviora, v. 394 , p. $1-7$.

Rougier, G.W., Garrido, A., Gaetano, L., Puerta, P., Corbitt, C., and Novacek, M.J., 2007a, A new triconodont from South America: American Museum Novitates, v. 3580, p. 1-17.

Rougier, G.W., Martinelli, A.G., Forasiepi, A.M., and Novacek, M.J., 2007b, New Jurassic mammals from Patagonia, Argentina: a reappraisal of australosphenidan morphology and interrelationships: American Museum Novitates, v. 3566, p. $1-54$

Salani, F.M., 2007, Aporte a la edad de la Formación Cañadón Asfalto, Chubut, Argentina: Resúmenes, 30 Simposio Argentino del Jurásico, p 71.

Salgado, L., Coria, R.A., and Heredia, S.E., 1997, New Materials of Gasparinisaura cincosaltensis (Ornithischia, Ornithopoda) from the Upper Cretaceous of Argentina: Journal of Paleontology, v. 71, p. 933-940.
Santa Luca, A.P., 1980, The postcranial skeleton of Heterodontosaurus tuck (Reptilia, Ornithischia) from the Stormberg of South Africa: Annals of the South African Museum, v. 79, p. 159-211.

Scheetz, R.D., 1999, Osteology of Orodromeus makelai and the phylogeny of basal ornithopod dinosaurs, unpublished Ph.D. dissertation: Bozeman, Montana State University, $186 \mathrm{p}$

Sereno, P.C., 1986, Phylogeny of the bird-hipped dinosaurs (Order Ornithischia): National Geographic Research, v. 2, p. 234-256.

Sereno, P.C., 1991, Lesothosaurus, "fabrosaurids," and the early evolution of Ornithischia: Journal of Vertebrate Paleontology, v. 11, p. 168-197.

Sereno, P.C., 1997, The origin and evolution of dinosaurs: Annual Review of Earth and Planetary Sciences, v. 25, p. 435-489.

Sereno, P.C., 2012, Taxonomy, morphology, masticatory function and phylogeny of heterodontosaurid dinosaurs: ZooKeys, v. 226, p. 1-225.

Sereno, P.C., and Arcucci, A.B., 1994, Dinosaurian precursors from the Middle Triassic of Argentina: Marasuchus lilloensis, gen. nov.: Journal of Vertebrate Paleontology, v. 14, p. 53-73.

Sereno, P.C., and Rao, C., 1992, Early evolution of avian flight and perching, p. New evidence from the Lower Cretaceous of China: Science, v. 255, p. $845-848$.

Sternberg, C.M., 1937, Classification of Thescelosaurus: a description of a new species: Proceedings of the Geological Society of America, v. 1936, p. 375 .

Thulborn, R.A., 1970, The systematic position of the Triassic ornithischian dinosaur Lycorhinus angustidens: Zoological Journal of the Linnean Society, v. 49 , p. $235-245$

Tykoski, R.S., and Rowe, T., 2004, Ceratosauria, in Weishampel, D.B., Dodson, P., and Osmólska, H., eds., The Dinosauria, $2 \mathrm{~d}$ ed.: Berkeley, University of California Press, p. 47-70.

Vickaryous, M.K., Maryańska, T., and Weishampel, D.B., 2004, Ankylosauria, in Weishampel, D.B., Dodson, P., and Osmólska, H., eds., The Dinosauria, 2d ed.: Berkeley, University of California Press, p. 363-392.

Virchow, H., 1919, Atlas and Epistropheus bei den Schildkröten: Sitzungsberichte der Gesellschaft Naturforschender Freunde zu Berlin, v. 1919, p. $303-332$.

Volkheimer, W., Gallego, O.F., Cabaleri, N.G., Armella, C., Narváez, P.L., Silva Nieto, D.G., and Páez, M.A., 2009, Stratigraphy, palynology, and conchostracans of a Lower Cretaceous sequence at the Cañadón Calcáreo locality, Extra-Andean central Patagonia: age and palaeoenvironmental significance: Cretaceous Research, v. 30, p. 270-282.

Von Meyer, H., 1857, Beiträge zur näheren Kenntnis fossiler Reptilien: Neues Jahrbuch für Mineralogie, Geologie und Paläontolgie, 1857, p. 532-543.

Weishampel, D.B., Dodson, P., and Osmólska, H., 2004, The Dinosauria, 2d ed.: Berkeley, University of California Press, $776 \mathrm{p}$.

Werning, S., 2012, The ontogenetic osteohistology of Tenontosaurus tilletti: PLoS One, v. 7, p. e33539.

White, M.A., 2009, The subarctometatarsus: intermediate metatarsus architecture demonstrating the evolution of the arctometatarsus and advanced agility in theropod dinosaurs: Alcheringa, v. 33, p. 1-21.

Woodward, H.N., Rich, T.J., Chinsamy, A., and Vickers-Rich, P., 2011, Growth dynamics of Australia's Polar dinosaurs: PLoS One, v. 6(8), p. e23339.

$\mathrm{Xu}, \mathrm{X}$., Wang, X.-L., and You, H.-L., 2000a, A primitive ornithopod from the Early Cretaceous Yixian Formation of Liaoning: Vertebrata PalAsiatica, v. 38, p. 318-325.

Xu, X., Zhou, Z., and Wang, X.-L., 2000b, The smallest known non-avian theropod dinosaur: Nature, v. 408, p. 705-708.

Xu, X., Norrel, M.A., Kuang, X., Wang, X., Zhao, Q., and Jia, C., 2004 Basal tyrannosaurids from China and evidence for protofeathers in tyrannosauroids: Nature, v. 431, p. 680-684.

Xu, X., Forster, C.A., Clark, J.M., and Mo, J., 2006, A basal ceratopsian with transitional features from the Late Jurassic of northwestern China: Proceedings of the Royal Society B, v. 273, p. 2135-2140.

Yates, A.M., 2003, The species taxonomy of the sauropodomorph dinosaurs from the Löwenstein Formation (Norian, Late Triassic) of Germany: Palaeontology, v. 46, p. 317-337.

You, H.-L., and Dodson, P., 2003, Redescription of neoceratopsian dinosaur Archaeoceratops and early evolution of Neoceratopsia: Acta Paleontologica Polonica, v. 48, p. 261-272.

You, H.-L., and Dodson, P., 2004, Basal Ceratopsia, in Weishampel, D.B., Dodson, P., and Osmólska, H., eds., The Dinosauria, 2d ed.: Berkeley, University of California Press, p. 478-493.

Zavattieri, A.M., Escapa, I.H., Scasso, R.A., and Olivera, D., 2010, Contribución al conocimiento palinoestratigráfico de la Formación Cañadón Calcáreo en su localidad tipo, provincia del Chubut, Argentina: $\mathrm{X}$ Congreso Argentino de Paleontología y Bioestratigrafía-VII Congreso Latinoamericano de Paleontología Resúmenes, La Plata, Argentina, p. 224. 
Zhang, F., Zhou, Z., Xu, X., and Wang, X., 2002, A juvenile coelurosaurian theropod from China indicates arboreal habits: Naturwissenschaften, v. 89, p. 394-398.

Zheng, X.-T., You, H.-L., Xu, X., and Dong, Z.-M., 2009, An Early Cretaceous heterodontosaurid dinosaur with integumentary structures: Nature, v. 458, p. 333-336.

Zhou, Z., and Farlow, J.O., 2001, Flight capability and habits of Confuciusornis, in Gauthier, J., and Gall, L.F., eds., New Perspectives on the Origin and
Early Evolution of Birds, New Haven, New Jersey, Special publication of the Peabody Museum of Natural History, Yale University, p. 237-254.

Zhou, Z., and Hou, L., 1998, Confuciusornis and the early evolution of birds: Vertebrata PalAsiatica, v. 36, p. 136-146.

Accepted 30 October 2015 